\title{
One-Pot Aqueous Synthesis of Fluorescent Ag-In-Zn-S Quantum Dot/Polymer Bioconjugates for Multiplex Optical Bioimaging of Glioblastoma Cells
}

\author{
Alexandra A. P. Mansur, ${ }^{1}$ Herman S. Mansur, ${ }^{1}$ \\ Sandhra M. Carvalho, ${ }^{1,2,3}$ and Anderson J. Caires ${ }^{1}$ \\ ${ }^{1}$ Center of Nanoscience, Nanotechnology and Innovation (CeNano ${ }^{2}$ I), Federal University of Minas Gerais (UFMG), \\ Belo Horizonte, $M G$, Brazil \\ ${ }^{2}$ Department of Preventive Veterinary Medicine, Veterinary School, Federal University of Minas Gerais (UFMG), \\ Belo Horizonte, MG, Brazil \\ ${ }^{3}$ Department of Physiology and Biophysics, ICB, Federal University of Minas Gerais (UFMG), Belo Horizonte, MG, Brazil
}

Correspondence should be addressed to Herman S. Mansur; hmansur@demet.ufmg.br

Received 20 July 2017; Revised 4 September 2017; Accepted 13 September 2017; Published 13 November 2017

Academic Editor: Maria P. Morales

Copyright (C) 2017 Alexandra A. P. Mansur et al. This is an open access article distributed under the Creative Commons Attribution License, which permits unrestricted use, distribution, and reproduction in any medium, provided the original work is properly cited.

\begin{abstract}
Cancer research has experienced astonishing advances recently, but cancer remains a major threat because it is one of the leading causes of death worldwide. Glioblastoma $(\mathrm{GBM})$ is the most malignant brain tumor, where the early diagnosis is vital for longer survival. Thus, this study reports the synthesis of novel water-dispersible ternary $\mathrm{AgInS}_{2}$ (AIS) and quaternary $\mathrm{AgInS}_{2}-\mathrm{ZnS}$ (ZAIS) fluorescent quantum dots using carboxymethylcellulose (CMC) as ligand for multiplexed bioimaging of malignant glioma cells (U-87 MG). Firstly, AgInS 2 core was prepared using a one-pot aqueous synthesis stabilized by CMC at room temperature and physiological pH. Then, an outer layer of $\mathrm{ZnS}$ was grown and thermally annealed to improve their optical properties and split the emission range, leading to core-shell alloyed nanostructures. Their physicochemical and optical properties were characterized, demonstrating that luminescent monodispersed AIS and ZAIS QDs were produced with average sizes of $2.2 \mathrm{~nm}$ and $4.3 \mathrm{~nm}$, respectively. Moreover, the results evidenced that they were cytocompatible using in vitro cell viability assays towards human embryonic kidney cell line (HEK 293T) and U-87 MG cells. These AIS and ZAIS successfully behaved as fluorescent nanoprobes (red and green, resp.) allowing multiplexed bioimaging and biolabeling of costained glioma cells using confocal microscopy.
\end{abstract}

\section{Introduction}

Despite indisputable progress in medicine in the recent decades, cancer remains as one of the most devastating diseases of the 21st century challenging scientists and professionals as the word "cancer" covers approximately 200 different types of disease [1-3]. In fact, it is far more likely that advances in science for early diagnosis will result in threating more cancers as "manageable" chronic diseases with patients maintaining a relative satisfactory quality of life [4].

Brain tumors are the most common cancer occurring among children (age 0-14) and the leading cause of cancerrelated deaths at that age, above leukemia statistics. Brain tumors are a diverse group of neoplasms that frequently carry a poor prognosis for patients [5, 6]. Glioblastoma (GBM, World Health Organization grade IV glioma) is the most prevalent and lethal primary intrinsic brain tumor. Unlike other solid tumor cell types, GBM widely and aggressively invades the surrounding brain but hardly metastasizes to other organs [7, 8]. Despite tremendous efforts to develop diagnostic tools and therapeutic avenues, the accurate early detection and effective treatment of brain tumors remains a difficult challenge to be overcome in the field of neurooncology. Currently, the prognosis for GBM tumor is at the extreme worst with mortality greater than $90 \%$ at 5 years, with a median survival of 12.6 months [9-11].

Modern neuroimaging tools are being applied to diagnose and grade brain tumors preoperatively, to plan and 
direct surgery intraoperatively, and to monitor and assess treatment response and estimating patient prognosis $[12,13]$. Current research in brain tumor imaging attempts to develop, validate, and clinically implement advanced neuroimaging techniques that can benefit in the diagnosis and the detection of early treatment inefficiencies [12]. Imaging techniques including magnetic resonance imaging (MRI), computed tomography (CT), and positron-emission tomography (PET) are the most common modalities for brain tumor diagnosis, characterization, and intraoperative imaging. Other techniques such as fluorescence imaging have been developed for intraoperative fluorescence-guided tumor resection. These imaging modalities can aid in delineating the boundaries between neoplastic and normal tissue, helping doctors determine the most suitable sequence of treatment $[9,10]$. Recently, theranostics, which is the combination of therapy and diagnosis, has become one of the primary keywords in cancer research, taking into account the fact that if cancer growth can be hampered during the diagnostic procedure, the subsequent cancer treatment would be facilitated because cancer growth is delayed or cancer burden is reduced [14].

To this end, nanotechnology offers a promising platform for the evolution of cancer molecular imaging strategies where nanomaterials can be used in the development of novel theranostic systems in oncology. Quantum dots (QDs) are being intensively studied as innovative class of nanoprobes for biomedical imaging because of their unique optical and electronic properties. Multiplexed molecular imaging relying on fluorescent QDs can reveal the tempospatial relationship among molecules by simultaneously staining several tumor biomarkers [6]. To overcome the obstacles of QDs for biomedical imaging, the physicochemical properties of QDs such as composition, size, shape, and surface characteristics associated with cytotoxicity have been comprehensively investigated $[6,15,16]$. However, despite the intense research in the realm of quantum dots for nanomedicine applications, the large majority of studies are based on Cd-containing semiconductor core (i.e., CdS, CdSe, and CdTe) synthesized using organometallic process at high temperature $[17,18]$. For that reason, their potential toxicity has become a subject of serious discussion and debate, without a definitive conclusion yet. Some studies have demonstrated that Cd-based QDs can degrade in a biological environment, releasing highly cytotoxic $\mathrm{Cd}^{2+}$ ions $[18,19]$. Therefore, over the past few years, a variety of Cd-free QDs have been produced from materials including zinc chalcogenides (i.e., $\mathrm{ZnSe}, \mathrm{ZnS}$ ), copper indium sulfide $\left(\mathrm{CuInS}_{2}\right)$, silver indium sulfide $\left(\mathrm{AgInS}_{2}\right.$, AIS), silver sulfide $\left(\mathrm{Ag}_{2} \mathrm{~S}\right)$, and core-shell nanostructures $\left(\mathrm{AgInS}_{2}-\mathrm{ZnS}\right.$, ZAIS) [17, 19-21]. Importantly, some of these QDs share many of the advantages of commonly used Cd-based QDs regarding their optical properties and photoluminescence stability, surface biochemistry, and colloidal stability. Hence, QDbased probes that comply with the full set of requirements for biomedical applications can be used to target cancer molecules with high specificity [22-24]. Although ternary semiconductor QDs (e.g., Ag-In-S) have been already prepared in water medium for biomedical applications [19, 20, 25-28] no report was found in the consulted literature where they were directly synthesized using polysaccharide-based biopolymers as surface capping ligands for in vitro imaging GBM cells.

Thus, in this study, a facile one-pot synthesis of novel Cdfree QDs based on AIS and ZAIS semiconductor nanocrystals produced by an eco-friendly aqueous process using carboxymethylcellulose simultaneously as stabilizing ligand and for surface biofunctionalization is presented. These colloidal nanoconjugates were cytocompatible and demonstrated fluorescent activity for effective multiplexed bioimaging of malignant glioma cells in vitro, as schematically depicted in Figure 1S (Graphical Abstract, Supplementary Material available online at https://doi.org/10.1155/2017/3896107). We endeavor that this research paves the way to develop new fluorescent biomarkers in nanomedicine for diagnosis, targeting and therapy of brain cancer tumors.

\section{Materials and Methods}

2.1. Materials. Zinc nitrate hydrate $\left(\mathrm{Zn}\left(\mathrm{NO}_{3}\right)_{2} \cdot 6 \mathrm{H}_{2} \mathrm{O}\right.$, $>99 \%)$, indium nitrate hydrate $\left(\mathrm{In}\left(\mathrm{NO}_{3}\right)_{3} \cdot x \mathrm{H}_{2} \mathrm{O}\right.$, In $=$ $28.5 \% \mathrm{wt}$ ), carboxymethylcellulose sodium salt (CMC, degree of substitution: 0.7 ; average molecular mass $=90,000 \mathrm{Da}$; medium viscosity: $180 \mathrm{cps}, 4 \%$ in $\mathrm{H}_{2} \mathrm{O}$ at $\left.25^{\circ} \mathrm{C}\right)$, 3- $(4,5-$ dimethylthiazol-2yl) 2,5-diphenyltetrazolium bromide (MTT, $>98 \%$ ), Triton $^{\mathrm{TM}} \mathrm{X}-100$, sodium dodecyl sulfate (SDS, $\geq 99.0 \%$ ), paraformaldehyde (95\%), and hydrochloric acid ( $\mathrm{HCl}, 37 \%)$ were purchased from Sigma-Aldrich (USA). Silver nitrate $\left(\mathrm{AgNO}_{3}, 99.9 \%\right)$ and sodium sulfide hydrate $\left(\mathrm{Na}_{2} \mathrm{~S} \cdot 9 \mathrm{H}_{2} \mathrm{O},>98 \%\right)$ were purchased from Synth (Brazil). Dulbecco's Modified Eagle Medium (DMEM), fetal bovine serum (FBS), phosphate buffered saline (PBS), penicillin $G$ sodium, streptomycin sulfate, and amphotericin-b were supplied by Gibco BRL (USA). Hydromount was purchased from Fisher Scientific Ltd. (UK). Human embryonic kidney (HEK 293T, American Type Culture Collection, ATCC ${ }^{\circledR}$ CRL-1573 ${ }^{\mathrm{TM}}$ ) cells were kindly provided by Professor M.F Leite (Department of Physiology and Biophysics, UFMG). Malignant glioma (U-87 MG) cells were purchased from Rio de Janeiro Cell Bank (ATCC ${ }^{\circledR}$ HTB- $^{\mathrm{TM}}{ }^{\mathrm{TM}}$ ).

Aforementioned chemicals were used without further purification, deionized water (DI water, Millipore Simplicity $^{\mathrm{TM}}$ ) with a resistivity of $18 \mathrm{M} \Omega \mathrm{cm}$ was used to prepare the solutions, and the procedures were performed at room temperature (RT, $23 \pm 2^{\circ} \mathrm{C}$ ), unless specified otherwise.

\subsection{Synthesis of Quantum Dot Conjugates}

2.2.1. Synthesis of AIS QDs (QD1 and QD2). CMC solution $(1 \% \mathrm{w} / \mathrm{v})$ was prepared by adding sodium carboxymethylcellulose powder $(0.5 \mathrm{~g})$ to a $50 \mathrm{~mL}$ of water and stirring at room temperature until complete solubilization occurred. $\mathrm{AgInS}_{2}$ (QD1) conjugates were synthesized via an aqueous route at room temperature as follows: $2 \mathrm{~mL}$ of CMC solution and $48 \mathrm{~mL}$ of deionized water were added to a flask and the solution stabilized at physiological $\mathrm{pH}(7.5 \pm 0.2)$. Under magnetic stirring, $0.33 \mathrm{~mL}$ of the silver precursor solution $\left(\mathrm{AgNO}_{3}, 1 \times 10^{-3} \mathrm{~mol} \cdot \mathrm{L}^{-1}\right)$ and $1.33 \mathrm{~mL}$ of indium precursor solution $\left(\mathrm{In}\left(\mathrm{NO}_{3}\right)_{3} \cdot x \mathrm{H}_{2} \mathrm{O}, 1 \times 10^{-3} \mathrm{~mol} \cdot \mathrm{L}^{-1}\right)$ were added to the flask and stirred for $1 \mathrm{~min}$. This stoichiometry of $\mathrm{Ag}$ : In 


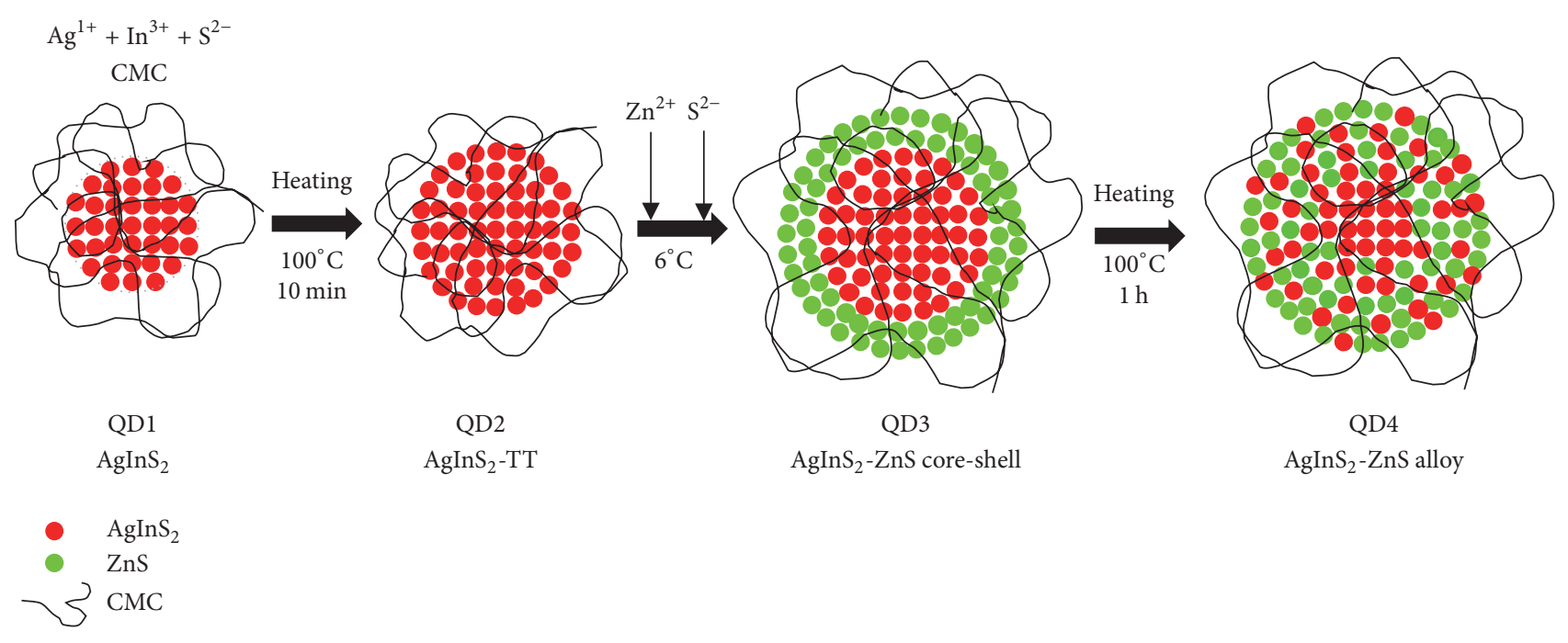

Figure 1: Procedure for fabrication Ag-In-S and Ag-In-Zn-S quantum dots.

molar ratio of 1: 4 gives the most intense emission for $\mathrm{AgInS}_{2}$ nanocrystals $[20,29,30]$. In the sequence, under vigorous stirring, $2.0 \mathrm{~mL}$ of sulfur solution precursor $\left(\mathrm{Na}_{2} \mathrm{~S} \cdot 9 \mathrm{H}_{2} \mathrm{O}, 1\right.$ $\left.\times 10^{-3} \mathrm{~mol} \cdot \mathrm{L}^{-1}\right)$ was dropped into the flask and stirred for $10 \mathrm{~min}$.

In order to improve the optical properties of $\mathrm{AgInS}_{2}$ cores (referred to as QD1 or $\mathrm{AgInS}_{2}$ ), some procedures were taken in following sequence: (a) thermal treatment (TT) of $\mathrm{AgInS}_{2}$ cores at $100 \pm 5^{\circ} \mathrm{C}$ for $10 \mathrm{~min}$ to annealing/growth of $\mathrm{AgInS}_{2}$ QDs (referred to as QD2 or $\mathrm{AgInS}_{2}$-TT); (b) $\mathrm{ZnS}$ shell growth overlaying $\mathrm{AgInS}_{2}$-TT cores (referred to as QD3 or $\mathrm{AgInS}_{2}-\mathrm{ZnS}$ core-shell); and (c) thermal treatment of $\mathrm{AgInS}_{2}-\mathrm{ZnS}$ core-shell structure at $100 \pm 5^{\circ} \mathrm{C}$ for $60 \mathrm{~min}$ leading to alloying (referred to as QD4 or $\mathrm{AgInS}_{2}-\mathrm{ZnS}$ alloy). Figure 1 summarizes the steps for the preparation of ZAIS QDs from AIS QDs that are described in Section 2.2.2.

2.2.2. Synthesis of ZAIS QDs ( $\operatorname{AgInS}_{2}-Z n S$, QD3, and QD4). In this step, initially an "adlayer" of $\mathrm{ZnS}$ was grown onto $\mathrm{AgInS}_{2}$-TT core reaching a core-shell nanostructure $\left(\mathrm{AgInS}_{2}\right.$ $\mathrm{ZnS}$ core-shell or QD3). Therefore, the previous AIS solution (QD2) was refrigerated at $6 \pm 2^{\circ} \mathrm{C}$ for at least $6 \mathrm{~h}$. Then, at $6 \pm 2^{\circ} \mathrm{C}$ and under stirring, a $1.25 \mathrm{~mL}$ of zinc precursor $\left(\mathrm{Zn}\left(\mathrm{NO}_{3}\right)_{2} \cdot 6 \mathrm{H}_{2} \mathrm{O}, 1 \times 10^{-3} \mathrm{~mol} \cdot \mathrm{L}^{-1}\right)$ was added dropwise $(10 \mu \mathrm{L}$ at each $10 \mathrm{~s})$ into $50 \mathrm{~mL}$ of QD2 suspension followed by addition of $1.25 \mathrm{~mL}$ of sulfur precursor $\left(\mathrm{Na}_{2} \mathrm{~S} \cdot 9 \mathrm{H}_{2} \mathrm{O}, 1\right.$ $\times 10^{-3} \mathrm{~mol} \cdot \mathrm{L}^{-1}$ ) in the same way (dropwise, $10 \mu \mathrm{L}$ at each $10 \mathrm{~s}$ ) and stirred for $20 \mathrm{~min}$. The resulting suspension (QD3, $\mathrm{AgInS}_{2}-\mathrm{ZnS}$ ) was reserved for $24 \mathrm{~h}$ at $6 \pm 2{ }^{\circ} \mathrm{C}$.

In the sequence, the QD3 suspension was heated for $1 \mathrm{~h}$ at $100 \pm 5^{\circ} \mathrm{C}$ to allow interdiffusion of $\mathrm{Zn}^{2+}$ ions from shell into the core and annealing, leading to the formation of $\mathrm{AgInS}_{2}$ ZnS alloys (QD4).

All of the QDs colloidal dispersions produced were stable, homogeneous, and light brown. The QD colloids were dialyzed for $24 \mathrm{~h}$ (with water changes after $2 \mathrm{~h}$ and $4 \mathrm{~h}$ ) against $3 \mathrm{~L}$ of DI water using a Pur-A-Lyzer ${ }^{\mathrm{TM}}$ Mega Dialysis Kit (Sigma, cellulose membrane with molecular weight cut-off filter, MWCO of 12,000 Da) under moderate stirring at room temperature. After purification, the QD dispersions were stored at RT until further use. Colloidal dispersions were concentrated using an Amicon ${ }^{\circledR}$ Ultra Filter (Millipore) with a 100,000 molecular mass $\left(M_{W}\right)$ cut-off cellulose membrane.

2.3. Characterization of Quantum Dot Conjugates. Ultraviolet-visible (UV-vis) spectroscopy measurements were performed using Perkin-Elmer, Inc. (USA) equipment (Lambda EZ-210) in transmission mode with samples in a quartz cuvette over a wavelength range between 600 and $190 \mathrm{~nm}$. All of the experiments were conducted in triplicate $(n=3)$ unless specifically noted, and the data were presented as the mean \pm standard deviation.

The photoluminescence spectroscopy (PL) of the conjugates was performed based on spectra acquired at RT using a violet diode laser module at $405 \mathrm{~nm}$ excitation wavelength $\left(\lambda_{\text {exc }}\right)$ (150 mW, Roithner LaserTechnik, Germany) coupled to a USB4000 VIS-NIR (visible-near infrared) spectrophotometer (Ocean Optics, Inc., USA). All of the tests were performed using a minimum of four repetitions $(n \geq 4)$. Quantum yield (QY) was measured according to the procedure using Rhodamine 6G (Sigma, USA) in ethanol as the standard at $\lambda_{\text {exc }}=405 \mathrm{~nm}$ [31]. Additionally, QD colloidal media were placed inside a "darkroom-chamber" where they were illuminated by a UV (ultraviolet) radiation emission bulb ( $\lambda_{\text {exc }}=365 \mathrm{~nm}, 6 \mathrm{~W}$, Boitton Instruments). Digital color images were collected when the QDs fluoresced in the visible range of the spectra.

Morphological characterization of QD nanostructures was based on the images, electron diffraction patterns (ED), and energy-dispersive X-ray spectra (EDX) using Tecnai G220-FEI (FEI Company, USA) transmission electron microscope (TEM) at an accelerating voltage of $200 \mathrm{kV}$. In all of the TEM analyses, the samples were prepared by placing a drop of a dilute QD suspension onto carbon-coated copper grids (Electron Microscopy Sciences, USA) and allowing them to dry at room temperature overnight. The QD size 
and size-distribution data were obtained based on the TEM images by measuring at least 150 randomly selected nanoparticles using image processing program (ImageJ, version 1.50, public domain, National Institutes of Health) [32].

X-ray diffraction (XRD) patterns were recorded using PANalytical (UK) Empyrean diffractometer $(\mathrm{Cu}-\mathrm{K} \alpha$ radiation with $\lambda=1.5406 \AA$ ). Measurements were performed in the $2 \theta$ range from 6 to $60^{\circ}$ with steps of $0.017^{\circ}$. For the sample preparation, concentrated colloidal QD dispersions were placed onto glass slides and oven-dried at $40 \pm 1^{\circ} \mathrm{C}$ for $12 \mathrm{~h}$.

Dynamic light scattering (DLS) and zeta potential (ZP) analyses were performed using ZetaPlus instrument (Brookhaven Instruments Corporation, $35 \mathrm{~mW}$ red diode laser light, wavelength $\lambda=660 \mathrm{~nm}$ ) with a minimum of ten replicates. The $\mathrm{ZP}$ measurements were performed at $25 \pm$ $2^{\circ} \mathrm{C}$ under the Smoluchowski approximation method with a minimum of ten replicates.

2.4. Biological Characterization of QD Conjugates. All of the biological tests were conducted according to ISO 109935:2009/(R)2014 (Biological evaluation of medical devices: tests for in vitro cytotoxicity) using kidney cell line of a human embryonic culture (HEK 293T) and malignant glioma cells (U-87 MG). HEK 293T (passage 18) and U-87 MG (passage 8) cells were cultured in DMEM with $10 \%$ FBS, penicillin G sodium (10 units $\left.\mathrm{mL}^{-1}\right)$, streptomycin sulfate $\left(10 \mathrm{mg} \mathrm{mL}^{-1}\right)$, and amphotericin-b $\left(0.025 \mathrm{mg} \mathrm{mL}^{-1}\right)$ in a humidified atmosphere of $5 \% \mathrm{CO}_{2}$ at $37^{\circ} \mathrm{C}$.

2.4.1. Evaluation of Cytotoxicity by MTT Cell Viability Assay. MTT (3-(4,5-dimethylthiazol-2yl) 2,5-diphenyl tetrazolium bromide) experiments were performed to evaluate the toxicity of QDs dispersions. HEK 293T and U-87 MG cells were plated $\left(1 \times 10^{4}\right.$ cells/well) in 96 -well plates. Cell populations were synchronized in serum-free media for $24 \mathrm{~h}$. After that, the media volume was suctioned and replaced with DMEM media containing $10 \%$ FBS for $24 \mathrm{~h}$. The samples of QD1, QD2, QD3, and QD4 colloidal solutions were added to individual wells at final concentrations of $2.5 \mathrm{nmol} \cdot \mathrm{L}^{-1}$ of QD nanoparticles $\left(\sim 1 \mathrm{mg} \mathrm{mL}^{-1}\right)$. For MTT assay, control samples were designed as follows: control group (cell culture with DMEM medium); positive control (1.0\% v/v Triton ${ }^{\mathrm{TM}} \mathrm{X}-100$ in PBS); and negative control (chips of sterile polypropylene Eppendorf, $1 \mathrm{mg} \mathrm{mL}^{-1}$, Eppendorf, Germany). After $24 \mathrm{~h}$, all media were aspirated and replaced with $60 \mu \mathrm{L}$ of culture media containing serum to each well and images of cells were acquired on an Leica DMIL LED (Germany) inverted microscope. Then $50 \mu \mathrm{L}$ of MTT $\left(5 \mathrm{mg} \mathrm{mL}^{-1}\right)$ was added to each well and incubated for $4 \mathrm{~h}$ in an oven at $37^{\circ} \mathrm{C}$ and $5 \% \mathrm{CO}_{2}$. Next, $40 \mu \mathrm{L}$ SDS solution $/ 4 \% \mathrm{HCl}$ was placed in each well and incubated for $16 \mathrm{~h}$ in an oven at $37^{\circ} \mathrm{C}$ and $5 \% \mathrm{CO}_{2}$. Then, $100 \mu \mathrm{L}$ was removed from each well and transferred to a 96-well plate. The absorbance was measured at $595 \mathrm{~nm}$ on iMark $^{\mathrm{TM}}$ Microplate Absorbance Reader (Bio-Rad) with a $595 \mathrm{~nm}$ filter. Percentage cell viability was calculated according to (1). The values of the controls (wells with cells and no samples) were set to $100 \%$ cell viability.

$$
\begin{aligned}
\text { Cell viability }= & \frac{(\text { Absorbance of sample and cells })}{(\text { Absorbance of control })} \\
& \times 100 \% .
\end{aligned}
$$

2.4.2. Cellular Uptake of QD Conjugates by Laser Scanning Confocal Microscopy: Internalization, Kinetics, and Multiplexed Images. The evaluation of the QDs conjugates as fluorescent biological probes was performed using confocal laser scanning microscopy after exposing HEK 293T and U87 MG cells to QD1 and QD4 samples. QD1 (AIS) with the lowest QY was chosen for cell imaging with two cell lines and cellular uptake kinetics to demonstrate the feasibility of using these QD conjugates for cell imaging due their unique optical emission properties. QD1 (AIS) and QD4 (ZAIS) were selected as the fluorescent species for spectrally multiplexed imaging of cells considering the detectable wavelength of PL emission. HEK 293 T cells on passage 19 and U-87 MG cells on passage 9 were plated $\left(5 \times 10^{5}\right.$ cells per well $)$ in 6 -well plate. The cells were incubated for 4 days in $5 \% \mathrm{CO}_{2}$ at $37^{\circ} \mathrm{C}$ and synchronized for $24 \mathrm{~h}$. Then, QD colloidal suspensions with the medium solution (DMEM with $10 \%$ FBS) were added to the cells and incubated in $5 \% \mathrm{CO}_{2}$ at $37^{\circ} \mathrm{C}$ from 30 min up to $120 \mathrm{~min}$ (in cellular uptake kinetics study), followed by washing with PBS. For evaluation of internalization and kinetics, QD1 was incubated at final concentration of $50 \mathrm{nmol} \cdot \mathrm{L}^{-1}$ of QD nanoparticles. For costained multiplexed imaging, QD1 and QD4 were incubated separately at final concentration of $50 \mathrm{nmol} \cdot \mathrm{L}^{-1}$ or QD1 and QD4 were incubated together, at the same concentration of each. In the sequence, the cells were fixed with paraformaldehyde $(4 \%)$ for $30 \mathrm{~min}$ and washed three times with PBS, and cover slips were mounted with Hydromount. Images were obtained with a Zeiss LSM Meta 510 confocal microscope (Carl Zeiss, Germany) using the water immersion (objective 63x Plan-Apo/1.4 NA, Numerical Aperture). For green-emission, argon laser was used to excite at $\lambda_{\text {exc }}=488 \mathrm{~nm}$ and emission was collected at 505-550 nm. For red-emitting QD, excitation was at $\lambda_{\text {exc }}=568 \mathrm{~nm}$ and emission at LP $585 \mathrm{~nm}$ (LP = low pass). For the reference control, cells were incubated only with the original medium with 10\% FBS (autofluorescence). Plot of intensity profiles and measurements of mean fluorescence intensity were performed using public domain image processing software (ImageJ software, version 1.50).

\section{Results and Discussion}

3.1. Characterization of Quantum Dot Conjugates. Here, carboxymethylcellulose was used as the ligand for stabilizing the ultra-small semiconductor nanocrystals in water media, which were characterized in situ by UV-vis spectroscopy. These QDs presented broad UV-vis absorption spectra with an onset at approximately $650 \mathrm{~nm}$ (Figure 2(a)). This relatively broad absorption edge has been reported in literature $[27,33,34]$ for AIS and ZAIS nanoparticles, which was generally associated with size distribution of QD produced 


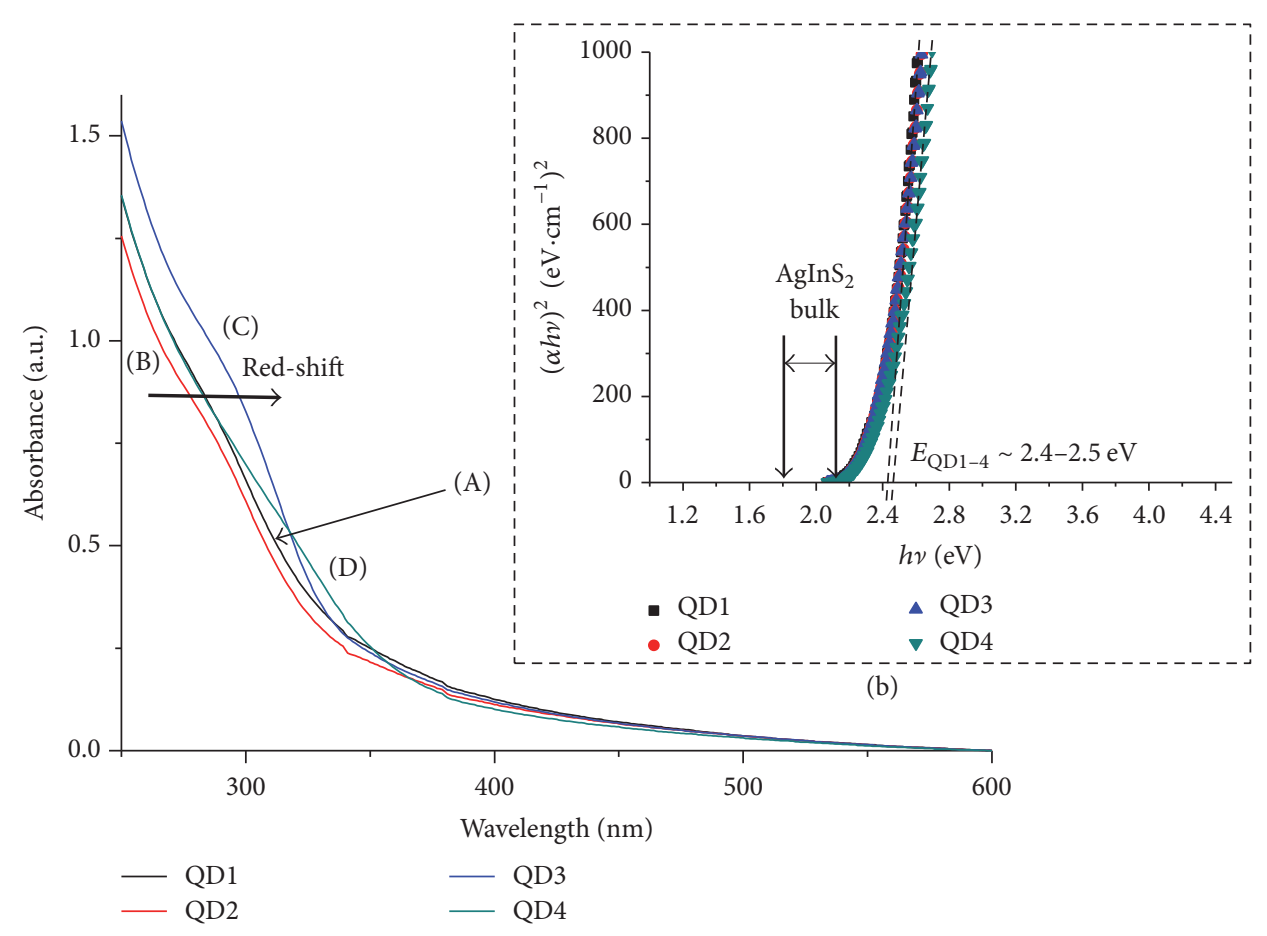

(a)

FIGURE 2: UV-vis absorption spectra (a) and optical absorption spectra (Tauc relation) (b) for QD1 (A), QD2 (B), QD3 (C), and QD4 (D).

$[35,36]$. The arrow in Figure 2(a) shows the "red-shift" in the absorption spectra of QD2 after overcoating with the $\mathrm{ZnS}$ passivating shell (QD3). Such behavior is caused by the growth of the wider bandgap ( $\mathrm{ZnS}$, bulk band gap $\left(E_{g}\right)=$ $3.61 \mathrm{eV}$ [37]) semiconductor, which may be interpreted as a partial leakage of the exciton from the $\operatorname{AgInS} \mathrm{I}_{2}$-core $\left(\mathrm{h}^{+} / \mathrm{e}^{-}\right.$, holes/electrons) into the $\mathrm{ZnS}$ shell through the heterojunction [38].

Band gap values for the prepared QDs were extracted from the UV-vis absorbance curves using the "Tauc relation" (Figure 2(b)). $\operatorname{AgInS}_{2}$ (AIS) is a direct bandgap semiconductor with $E_{g}$ ranging from $1.8 \mathrm{eV}$ (tetragonal) to $2.1 \mathrm{eV}$ (orthorhombic) $[27,39]$. The estimated $E_{\mathrm{QD}}$ (QD band gap) values were between $2.4 \mathrm{eV}$ and $2.5 \mathrm{eV}$, which are larger than that of the bulk values $\left(E_{g}=1.8-2.1 \mathrm{eV}\right)$ due to the quantum confinement effect.

In order to access the morphological features, the sizes, and the elemental composition of the QDs, TEM analysis coupled with EDX was performed. $\operatorname{AgInS}_{2}$ core (AIS, QD1, Figure 3(a)) and quaternary alloyed $\mathrm{AgInS}_{2}-\mathrm{ZnS}$ (ZAIS, QD4, Figure 3(b)) typical images revealed the formation of relatively monodispersed nanoparticles with reasonable spherical shape. The clear continuous lattice fringes obtained by electron diffraction in the HRTEM (high-resolution transmission electron microscopy) images demonstrated the single-crystalline nature of the QDs. The histograms of nanoparticle size distributions (Figures 3(c) and 3(d)) indicated the average size of $2.2 \pm 0.4 \mathrm{~nm}$ and $4.3 \pm 0.5 \mathrm{~nm}$ for QD1 and QD4, respectively. The observed increasing in diameter was expected by considering the growth of the $\mathrm{ZnS}$ shell over the nanocrystal core. EDX measurements confirmed the presence of Ag, In, and S in ternary QD1 and the incorporation of $\mathrm{Zn}$ in the alloyed QD4 (Figures 3(e) and 3(f)). For QD1, EDX analysis indicated an average molar ratio of $[\mathrm{Ag}]:[\mathrm{In}]=1: 4.3$, which is in good agreement with the precursor molar ratio for metal cations [1:4].

The XRD pattern indicated three broadened and weak reflections in ternary core (QD1, Figure 4(b)) and quaternary alloyed (QD4, Figure 4(c)) samples, due to the small particle size, overlapped with the broad band present at $2 \theta \sim 21.8^{\circ}$ (Figure 4(a)) that is characteristic of the CMC polymer used for the chemical stabilization of the QDs [40]. Based on reflection positions, the orthorhombic crystal phase was suggested for $\operatorname{AgInS}_{2}$ nanoparticles. However, as reported in literature $[27,41]$, the occurrence of other AIS phases cannot be either ruled out or confirmed due to the large width of the reflections. It is clear that the diffraction peaks of ZAIS nanocrystals (QD4) were shifted to higher angles in comparison to $\operatorname{AgInS}_{2}$ core (QD1) due to $\mathrm{ZnS}$ alloying with the reflections located between the corresponding peaks of the bulk orthorhombic AgInS, (International Centre for Diffraction Data, ICDD 25-1328) and cubic $\mathrm{ZnS}$ (ICDD 80-0020). Therefore, this feature confirmed that the QD4 (Figure 4(c)) formed an alloyed solid solution and not a mixture of $\mathrm{AgInS}_{2}$ and $\mathrm{ZnS}$ nanoparticles $[21,42]$.

Typical room temperature PL spectra of the quantum dots and QY results of QD1 to QD4 are presented in Figure 5. The spectra (Figure 5(a)) indicated that luminescence is based on defect-activated sites, where no excitonic emission was observed. In addition, "Full Width at Half Maximum" (FWHM) was larger than $100 \mathrm{~nm}$, which is consistent with 


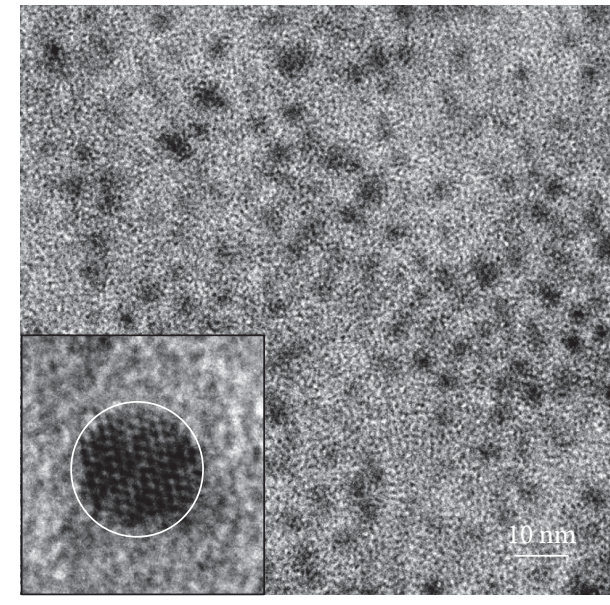

(a)

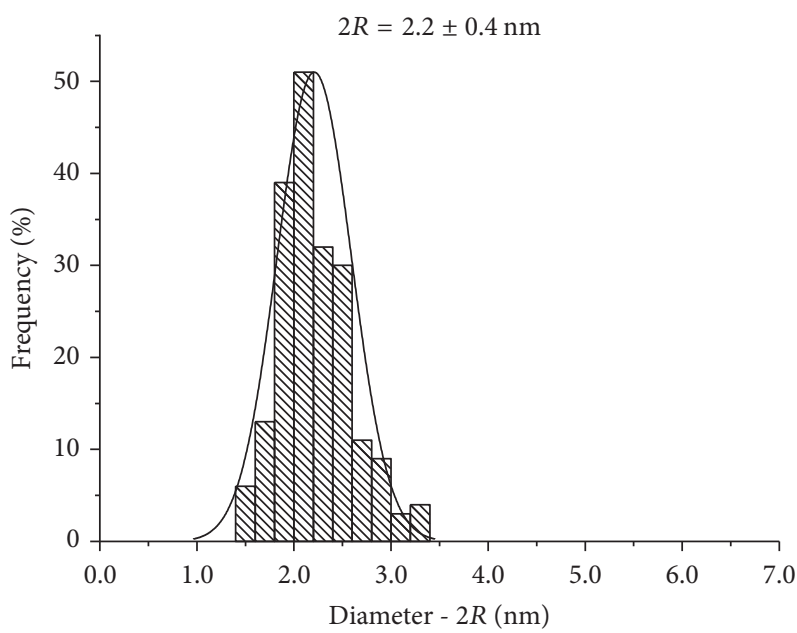

(c)

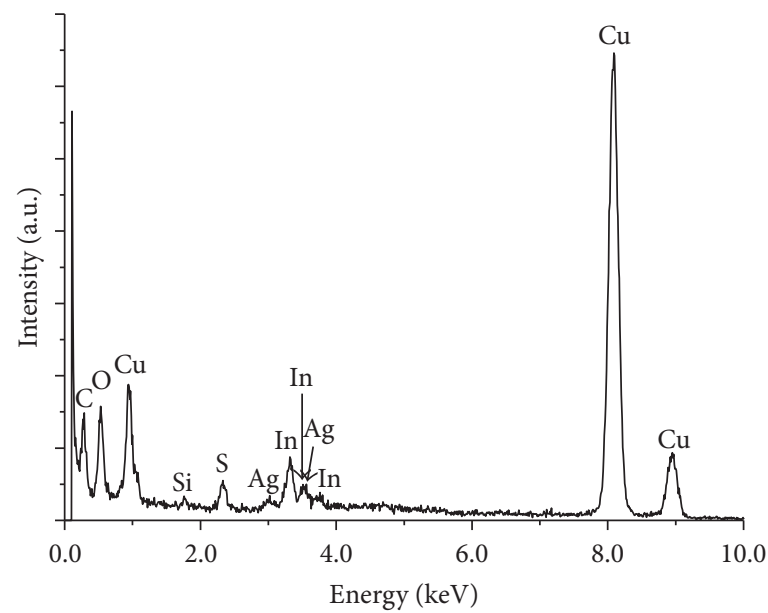

(e)

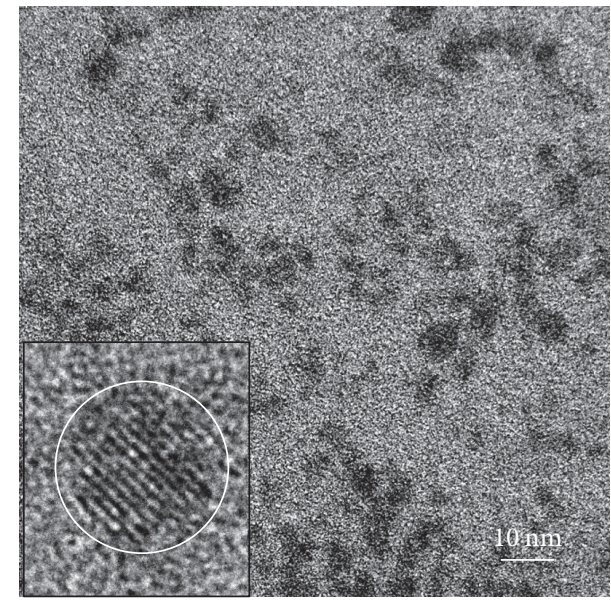

(b)

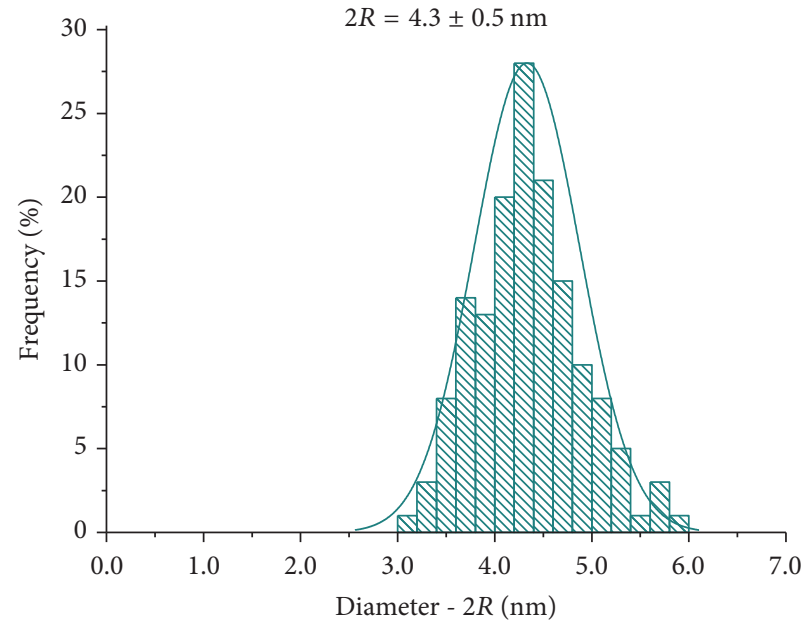

(d)

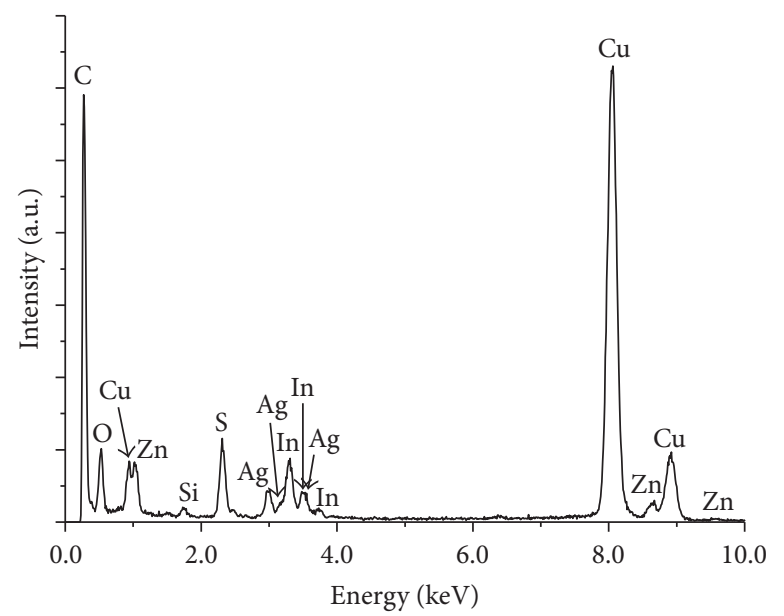

(f)

FIGURE 3: TEM image (inset: HRTEM picture) for QD1, AIS core (a) and QD4, ZAIS (b), histograms of size distribution for QD1 (c) and QD4 (d), and EDX spectra for QD1 (e) and QD4 (f). 


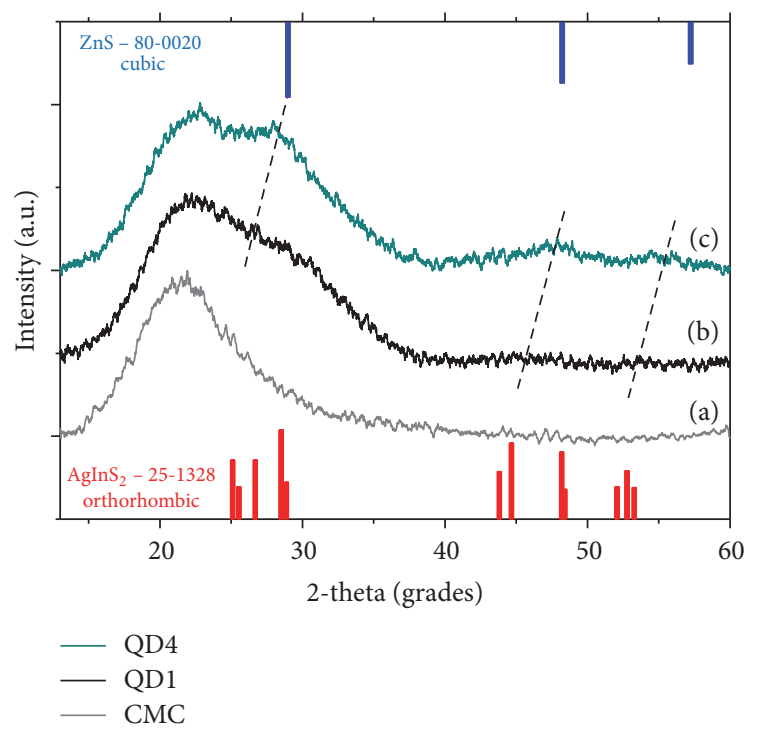

FIGURE 4: XRD patterns of CMC ligand (a), QD1 (AIS) (b), and QD4 (ZAIS) (c).

previous reports for Ag-In-S- and Zn-Ag-In-S semiconductor nanocrystals $[43,44]$.

According to the literature [29, 41] emissions of I-IIIVI nanocrystals are dominated by radiative recombination related to intrinsic donor-acceptor defects due to the failure of aligned orientation between Ag and In, in addition to nonradiative pathways from surface defects due to the high surface to volume ratio of QDs. Thermal treatment (QD1 $\rightarrow$ QD2) and shell growth (QD2 $\rightarrow$ QD3) reduced the surface trap states that cause the nonradiative pathways increasing the radiative emissions, as could be clearly seen by the increase of the PL intensity (Figure 5(a)) and QY values (Figure 5(b)). Besides passivating dangling bonds on QD surface, $\mathrm{ZnS}$ adlayer also promoted a blue-shift of the emission spectrum. Finally, thermal treatment of core-shell structure (QD3 $\rightarrow$ QD4) greatly improved photoluminescence intensity associated with interdiffusion of $\mathrm{Zn}$ ions into the AIS lattice upon alloying process and further annealing [20]. In this sense, the proposed strategy of improving optical properties of $\mathrm{AgInS}_{2}$ by a sequence of steps was effective. Despite the relative low values of QY (ca. $0.2 \%-1.0 \%)$, which is commonly observed for $\mathrm{QD}$ produced in water medium at room temperature mostly due to the density of crystalline and surface defects, the drastic increase of approximately $200 \%$ and $400 \%$ after the formation of the core-shell nanostructure and after the alloying-annealing process, respectively, is remarkable.

Thus, it is important to highlight that, compared with previous reported studies $[20,27,28]$, mostly based on heating up, hot injection, and organic processes, these $\mathrm{AgInS}_{2}$ QDs were produced using a facile one-step synthesis in aqueous media based on carboxymethylcellulose as polymer stabilizer, which offer several advantages: (a) more reproducible; (b) low-cost; (c) environment friendly; (d) commercially availability and abundance; (e) biocompatibility for further biomedical applications. However, a facile and "green" mild process using aqueous medium for the preparation of $\mathrm{AgInS}_{2}$ /polymer nanoconjugates with high luminescent properties (i.e., PL quantum yield, QY > 40\%) for augmenting bioimaging sensitivity is beyond the scope of the current study and remains a challenge for the future researches. Nonetheless, this is not a restriction, and QDs produced by aqueous processes with lower values of QY (i.e., typically $<5 \%$ ) have been successfully applied for numerous applications in bioimaging (e.g., confocal microscopy, flow cytometry) [16, 24, 45].

For biological applications, it widely known that size, shape, composition, and surface chemistry of nanoparticles have important roles in the biological responses of cells, tissues, and organs. Nanoparticle surface charge was determined by zeta potential $(\xi)$ measurements. The $\xi$-values for the synthesized nanoconjugates were between $-43 \mathrm{mV}$ and $-46 \mathrm{mV}$, which indicated the predominance of negatively charged surface due to the carboxylic groups $\left(\mathrm{R}-\mathrm{COO}^{-}\right)$ of anionic CMC ligand at physiological $\mathrm{pH}\left(\mathrm{p} k_{a} \sim 4.3\right)$ $[46,47]$. In addition, the zeta potential ( $\xi$-values) values lower than $-40 \mathrm{mV}$ indicated that the nanoparticles were electrostatically stabilized by the cellulose-modified polymer ligand as a colloidal nanoconjugate. The DLS technique was used to evaluate hydrodynamic sizes of the colloidal QDs in the medium. After the synthesis, in water medium at physiological $\mathrm{pH}$, the sum of contribution of QD inorganic core with the CMC organic shell and its interactions with the surrounding medium resulted in a hydrodynamic diameter ranging from $38 \mathrm{~nm}$ to $48 \mathrm{~nm}$. These results indicated that colloidal QD nanoconjugate suspensions contain individual nanoparticles electrostatically stabilized with negative surface charge.

In order to investigate the possible changes of surface charges and hydrodynamic sizes of QD1 and QD4 nanoconjugates immersed in the biological media for MTT and cellular uptake assays, ZP and DLS measurements were performed after $30 \mathrm{~min}$ of incubation (DMEM with $10 \%$ FBS). The DMEM contains inorganic salts, amino acids, vitamins, and D-glucose and is usually supplemented with FBS, which is a complex mixture (i.e., growth factors, proteins, vitamins, trace elements, and hormones) important for the growth and maintenance of cells [48-50]. After incubation with DMEM (with 10\% FBS), the average zeta potential measured for both systems decreased from ca. $-45.0 \mathrm{mV}$ to $-5.0 \mathrm{mV}$ and the hydrodynamic radius was reduced from ca. $40 \mathrm{~nm}$ to $20 \mathrm{~nm}$. These changes are associated with the overall balance of the neutralization of CMC polymer surface charges by inorganic salts and interaction of QD polymeric shell with the biomolecules from DMEM and FBS. Thus, QDs in the medium of biological assays are not agglomerated and coated with an hybrid shell (CMC-biomolecules-ions) that stabilize the near neutral QD surfaces by steric hindrance at sizes of approximately $20 \mathrm{~nm}[51,52]$.

\subsection{Biological Characterization of QD Conjugates}

3.2.1. Evaluation of Cytotoxicity by MTT Cell Viability Assay. The cytotoxicity of the heavy-metal free AIS (QD1 and QD2) and ZAIS (QD3 and QD4) nanoconjugates was assessed using the enzyme-based MTT. According to the study 


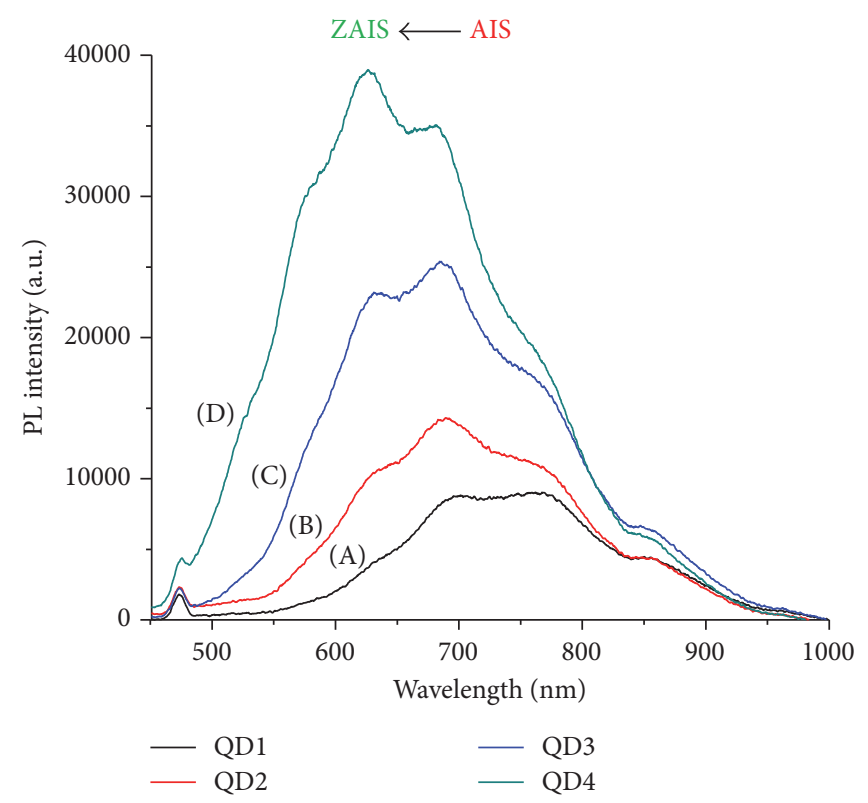

(a)

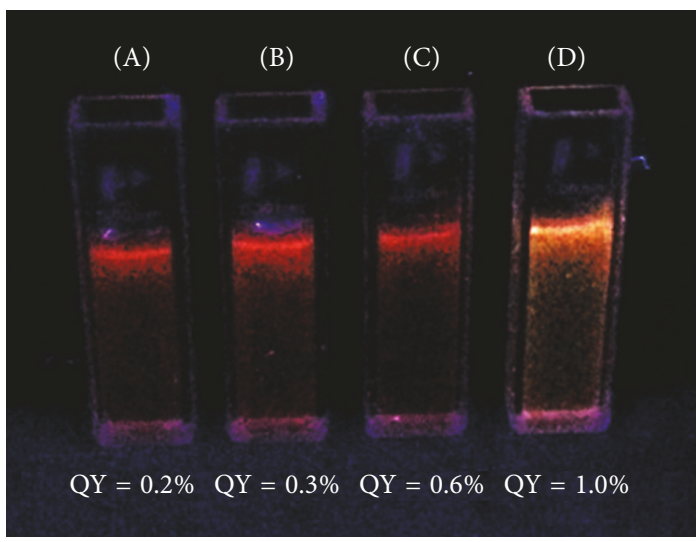

(b)

FIGURE 5: Photoluminescence spectra (a) and digital image of QD colloidal solutions excited by ultraviolet light $\left(\lambda_{\text {exc }}=365 \mathrm{~nm}\right)$ and QY values (b) obtained from QD1 (A), QD2 (B), QD3 (C), and QD4 (D) nanoconjugates.

recently published [18], MTT assay has been the predominant assay for in vitro evaluation of nanomaterials for biomedical applications [53-55]. Two cell lines, HEK 293T and U-87 MG, were used in the experiments. HEK 293T is a permanent cell line established from primary embryonic human kidney that is widely used as cell model and is very useful for transfection experiments, as they have a higher transfection efficiency than other cell lines, making it a common choice of cultures for biological research. The U-87 MG cell line is human primary glioblastoma cell line that is commonly used for brain cancer research [56]. The choice of use malignant glioma cells is due to the high lethality of brain tumors and the limited treatment options currently available [57] that demands studies of novel nanomaterials for targeting, detection, and treatment of brain tumors at the same time, which will be helpful to the earliest diagnosis and prolong survivability for patients.

The results of HEK 293T (Figure 6(a)) and U-87 MG (Figure 7(a)) cell lines in contact with the quantum dot-CMC nanoconjugates demonstrated that no significant differences in the cell viability compared to the control were detected (within the statistical variation). All of the samples presented cell viability responses typically above $90 \%$, indicating the nontoxicity of these bioconjugates. Even HEK 293T cells, which are more susceptible to be affected by the physicochemical characteristics of the nanoparticles due to the permeability of their membranes [58], presented cell viability higher than $94 \%$ at the concentration of nanoconjugates of $1.0 \mathrm{mg} \mathrm{mL}^{-1}$ after incubation for $24 \mathrm{~h}$. Optical images of the cells before (Figure 6(b)) and after incubation with QD1 nanoconjugates are in agreement with MTT results presenting more than $90 \%$ of cell confluence for HEK 293T cells (Figure 6(c)) and above $80 \%$ for U-87 MG cells before
(Figure 7(b)) after (Figure 7(c)) incubation. Similar results of cell confluence were obtained for the other nanoconjugate samples in contact with HEK 293T and U-87 MG cells (Figures 2S and 3S, Supplementary Material). In addition, qualitative morphological evaluation of the cells after incubation for $24 \mathrm{~h}$ with QDs was performed in zoomed-in images of the cells (Figures 4S and 5S, Supplementary Material) according to the scoring system described in ISO 10933-5, where grade 0 corresponds to none reactivity and grade 4 corresponds to severe reactivity. The changes observed for all nanoconjugates and cell types under evaluation can be graded as 1 (Slight), which means "not more than $20 \%$ of the cells are round, loosely attached and without intracytoplasmatic granules, or show changes in morphology; occasional lysed cells are present; only slight growth inhibition observable." The evaluation of grade 1 of our samples is considered a noncytotoxic effect according to ISO 10933-5. Thus, these nanoconjugates designed and produced with Cd-free inorganic core (AIS and ZAIS) and directly stabilized with carboxymethylcellulose ligand via aqueous route at physiological $\mathrm{pH}$ hold promise for biomedical bioimaging and targeting of cancer cells. However, the in vitro MTT assay was specifically used to evaluate the mitochondrial function and cell viability as a preliminary quantitative assessment of the cytocompatibility towards these nanoconjugates and further studies are required before in vivo or clinical applications.

\subsubsection{Cellular Uptake of QD Conjugates by Laser Scanning Confocal Microscopy}

(1) Cell Imaging and Kinetics of Cellular Uptake. In this study, in order to demonstrate the unique optical properties of quantum dots as compared to conventional dyes, AIS 


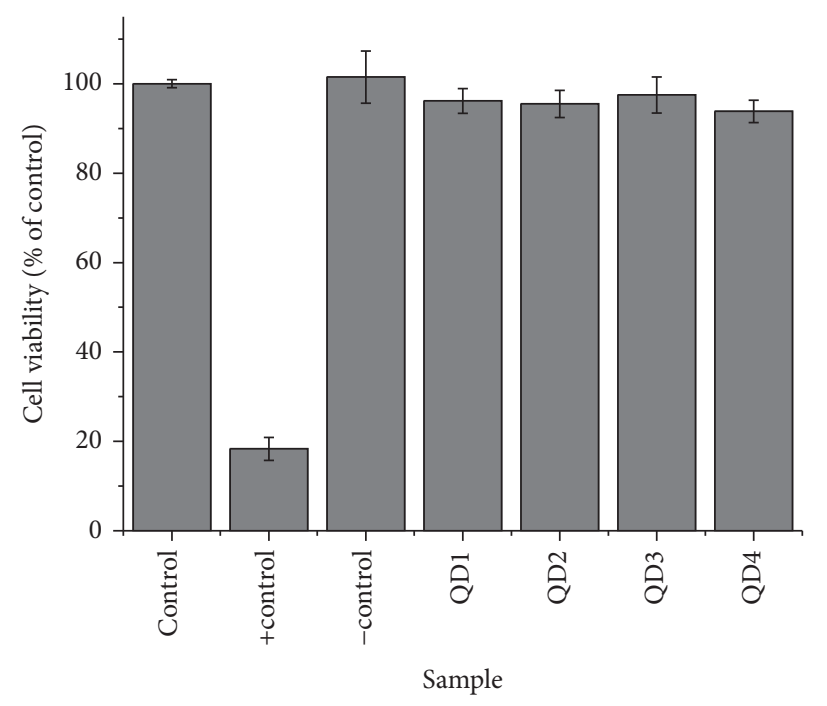

(a)

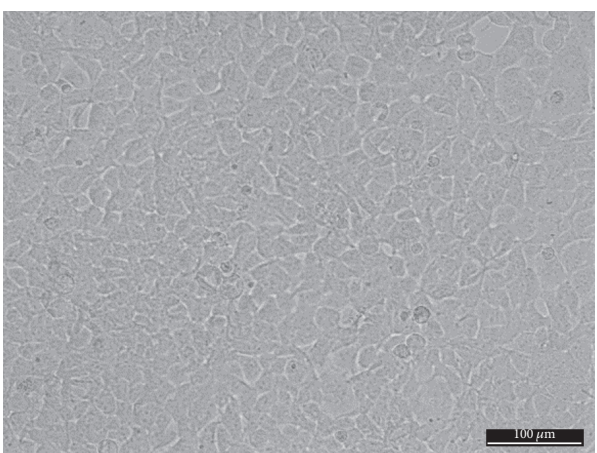

(b)

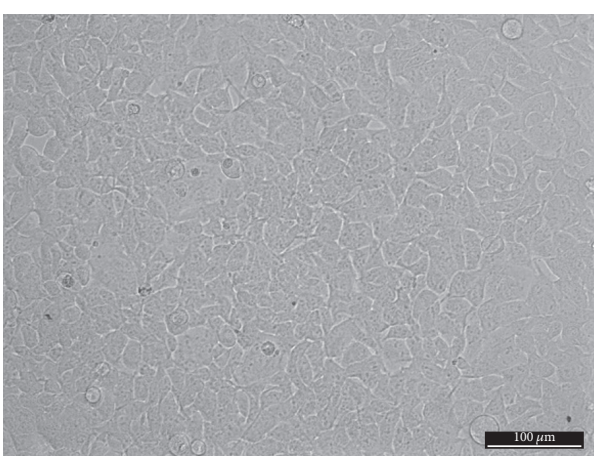

(c)

FIGURE 6: HEK 293T cell viability response by MTT assay after $24 \mathrm{~h}$ of incubation in direct contact with the QD nanoconjugate samples (a). HEK 293T cells images in control (b) and QD1 sample (c) (scale bar $=100 \mu \mathrm{m})$.

nanoparticles with low QY (QD1, AgInS 2 , QY = 0.2\%) were used as biological biomarkers and for cellular uptake evaluation using confocal laser scanning microscopy performed after incubation with HEK 293T and U-87 MG cells.

Distinct from AIS/ZAIS QDs reported in literature that required biological targeting vector and high quantum yield for allowing cellular imaging $[20,44]$, the novel $\mathrm{AgInS}_{2}$ nanoconjugates developed in this study were effectively internalized by HEK 293T and U-87 MG cells, which showed clear PL red-emission after 30 min of incubation (Figure 8). For both cell lines, PL emission associated with cellular localization of AIS nanoconjugates was examined using intensity fluorescence profiles obtained using image process software (ImageJ, v1.50). Thirty minutes after cellular uptake of HEK 293T and U-87 MG cells, the distribution of AIS conjugates fluorescence emission was observed at cytosol with no obvious fluorescence in their nuclei (Detail I, Figure 8(a)) and no clear evidence of specific intracellular localization. In addition, despite the scattered red fluorescence in the cytoplasmic matrix, some high fluorescent areas were observed in the cytoplasm that may suggest the presence of vesicles filled with QDs (white arrows, Detail II, Figure 8(b)).
However, in order to prove this hypothesis, costaining vesicles components is necessary.

Also, the kinetics of cellular uptake of QD1 in glioblastoma cells (U-87 MG) were evaluated (Figure 9). Confocal fluorescent images (Figure 9(b)) were taken after $30 \mathrm{~min}$, $60 \mathrm{~min}$, and $120 \mathrm{~min}$ of incubation with the nanoconjugates and mean fluorescence intensity (MFI, Figure 9(c)) was calculated using image processing software (public domain, ImageJ, v.1.5). A significant enhancement of the fluorescence intensities associated with the increase of incubation time from $30 \mathrm{~min}$ to $60 \mathrm{~min}$ (two-sample $t$-test, one tailed, with significance level $(\alpha) 0.025$ at 29 degrees of freedom) was detected. It is demonstrated that these nanoparticulate systems not only effectively penetrated through cell membranes allowing biolabeling but also proved the continuing endocytosis by the cells with further intracellular scattered distribution within the cytoplasmic matrix after $60 \mathrm{~min}$ of contact of QD with cells. At 120 min of incubation, it was observed that the mean fluorescence intensity was not significantly distinct from the obtained at $60 \mathrm{~min}$ of incubation (twosample $t$-test, one tailed, with significance level $(\alpha) 0.025$ at 29 degrees of freedom), suggesting that the saturation stage 


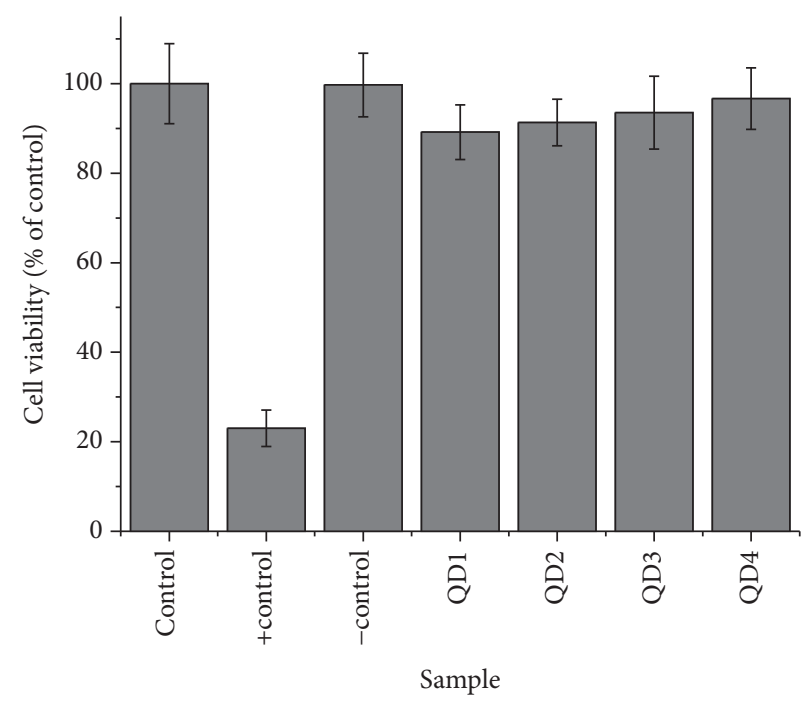

(a)

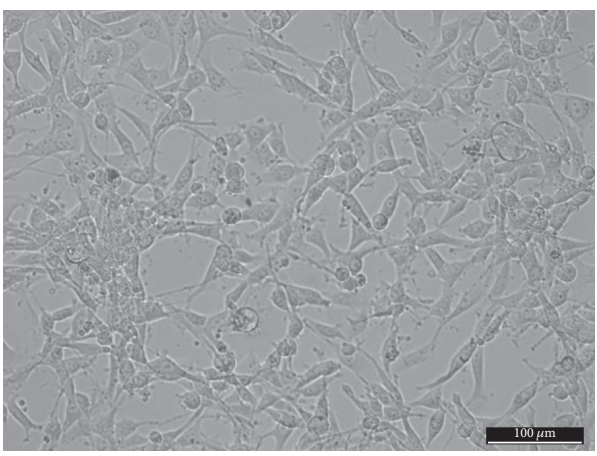

(b)

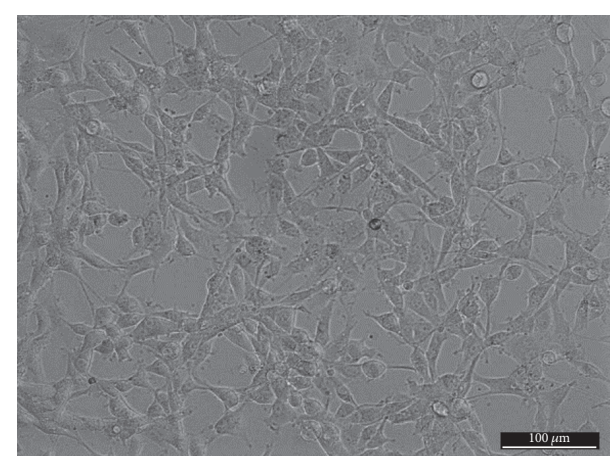

(c)

FIGURE 7: U-87 MG cell viability response by MTT assay after $24 \mathrm{~h}$ of incubation in direct contact with the QD nanoconjugate samples (a). U-87 MG cells images in control (b) and QD1 sample (c) (scale bar $=100 \mu \mathrm{m})$.

of intracellular uptake was reached [59]. In addition, for all evaluated incubation times, the cells demonstrate normal and clear morphology (Figure 9(a)).

(2) Multiplexed Bioimaging. The unique optical and electronic properties of quantum dots, such as high brightness, high chemical and photostability, continuous absorption, and relative narrow emission bandwidth, make them ideal choice as labels to develop fluorescent-based characterization techniques for detection and imaging cancer cells and tissues. In addition, QDs can be synthesized with distinct emission colors (i.e., multicolor nanoprobes via chemical composition and sizes) conjugated with functional biomolecules (e.g., antibodies and peptides) providing multiplexing capabilities to simultaneously identifying multiple biological targets of cancer cells and tissue for a myriad of applications in oncology $[9,10,60-64]$. In order to investigate the potential of the AIS (QD1) and the ZAIS (QD4) quantum dots for spectrally multiplexed imaging, the U-87 MG glioblastoma cells treated separately with these QDs were imaged by confocal microscopy and the fluorescent signals from the redemitting (AIS) and the green-emitting (ZAIS) were resolved by using spectrally matched filters (505/550 and LP 585). Based on the cell images depicted in Figure 10, the results demonstrated that the potential of using the 2-dimensional encoded QDs for spectrally multiplexed imaging and the images of cell costained with AIS + ZAIS (QD1 + QD4) is shown in Figure 11 that demonstrated the feasibility of combining these QDs for multiplexed bioimaging.

It is important to highlight that these results of multiplexed imaging by confocal microscopy relied on the exceptional optical properties of the water-soluble and cytocompatible QD nanoconjugates (i.e., red-emitting, AIS, and green-emitting, ZAIS). This strategy can be transferred to other characterization techniques for cancer biomarker detection such as flow cytometry (FC), immunohistochemistry (IHC), immunohistofluorescence (IHF), image guided surgery, and steady state fluorescence [9, 10,61-65]. Certainly, further studies are required to exploit the myriad of possibilities for producing cadmium-free QD nanoconjugates using aqueous processes with tunable PL properties (ranging from infrared to ultraviolet emission) via nanocrystal size and chemical composition, alloying and doping, coreshell nanostructures, processing routes, capping ligands, and 


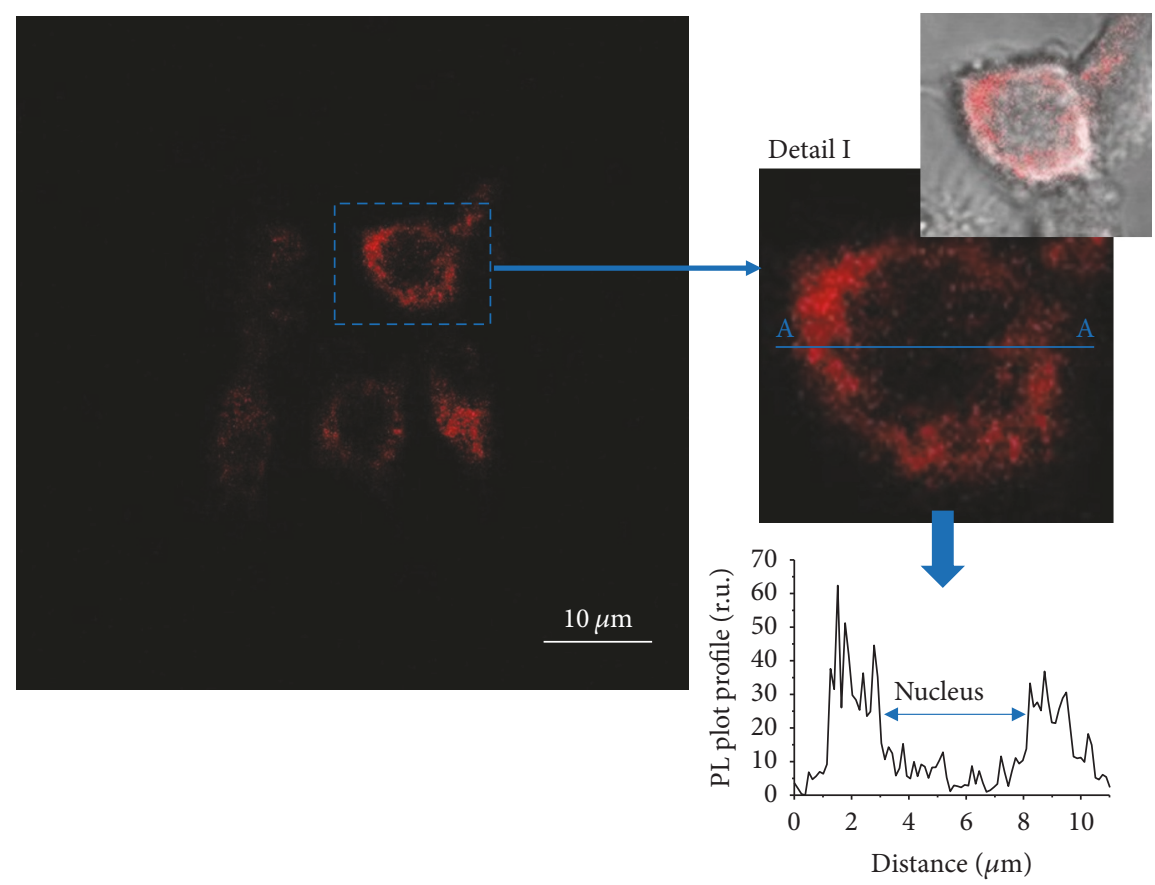

(a)
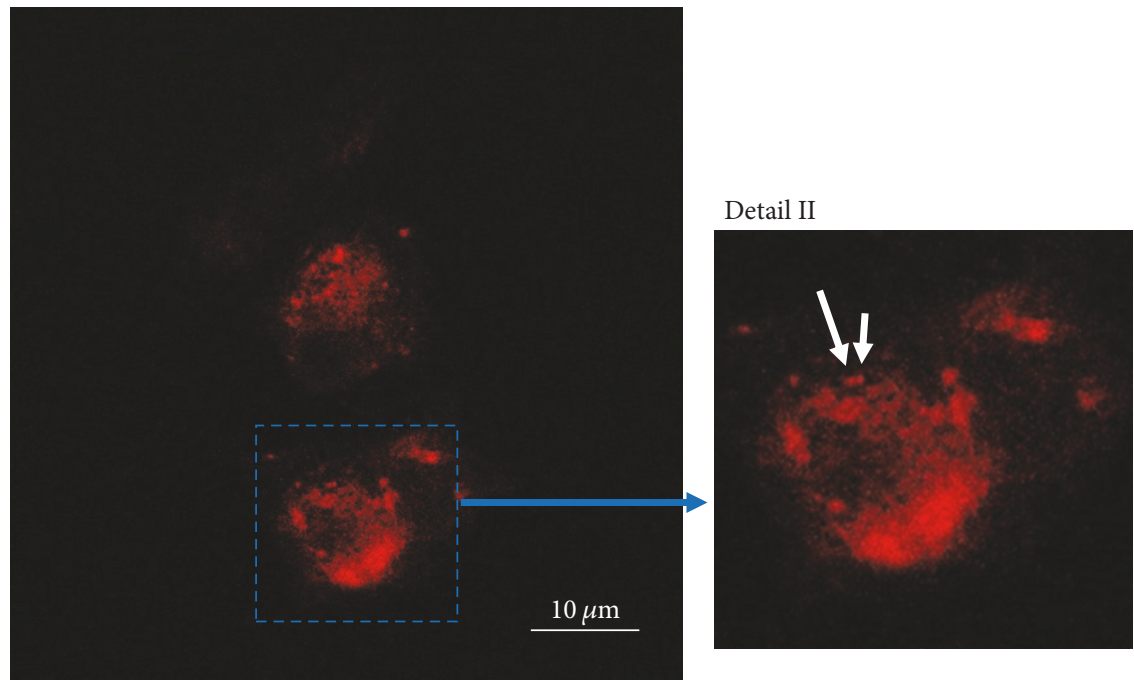

(b)

FIGURE 8: Confocal microscopy imaging of the cellular uptake of the AIS (QD1) nanoconjugates in the U-87 MG (a) and HEK 293T (b) cells. Detail I: intensity fluorescence profile along A-A line U-87 MG cell line indicating cellular localization of AIS nanoconjugates. Detail II: white arrows pointing out high fluorescent areas that may suggest the presence of vesicles filled with QDs.

others. To that end, a scenario could be envisioned for the future in which the use of multicolor QD-based fluorescent nanoconjugates could enhance the sensitivity, specificity, and multiplexing capabilities of molecular histopathology and early diagnosis of cancer for in vitro, in vivo, ex vivo applications. In particular, patients with glioblastoma (GBM), an extremely aggressive clinical phenotype of brain cancer, will undoubtedly benefit from the development of a new generation of diagnosis and therapies based on QD nanoconjugates with multiplexing technologies.

\section{Conclusions}

In this work a facile and eco-friendly method for synthesizing novel ternary $\operatorname{AgInS}_{2}$ (AIS) and quaternary $\operatorname{AgInS}_{2}$ $\mathrm{ZnS}$ (ZAIS) fluorescent colloidal nanocrystals with carboxymethylcellulose (CMC) as capping ligand using a onepot aqueous processing route at room temperature and physiological $\mathrm{pH}$ was developed. The formation of colloidal semiconductor solution was monitored in situ by UVvis spectroscopy, where the initial blue-shift of spectrum indicated the production of stable AIS and the posterior 


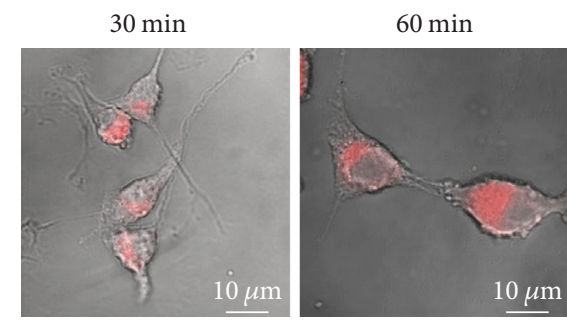

(a)
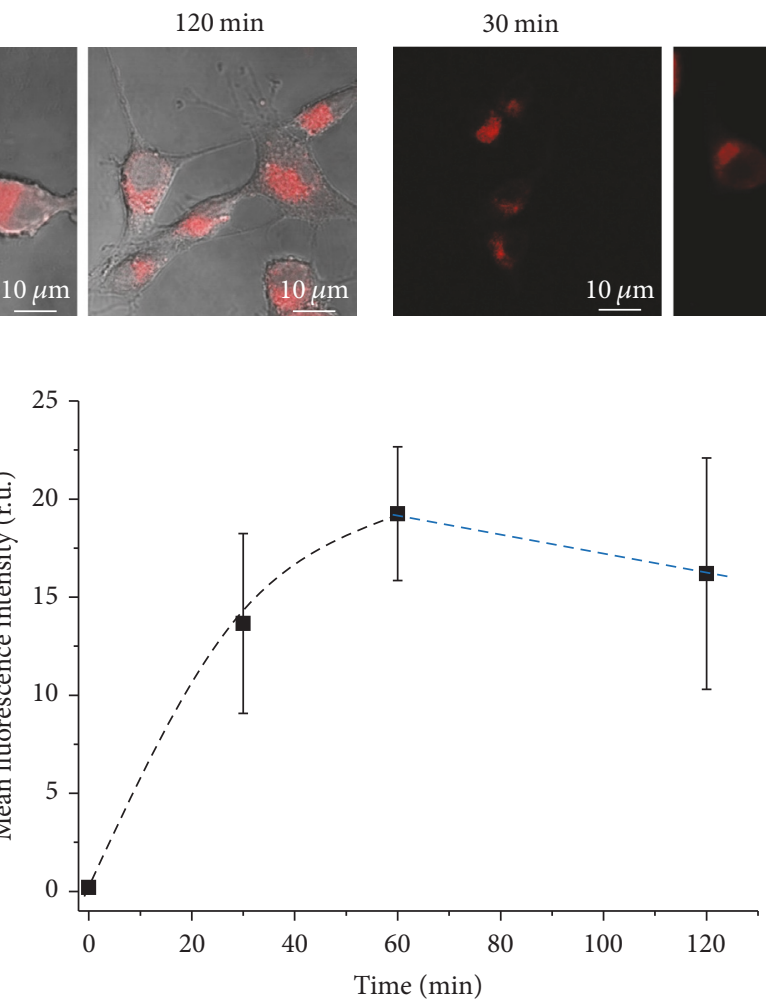

$60 \mathrm{~min}$
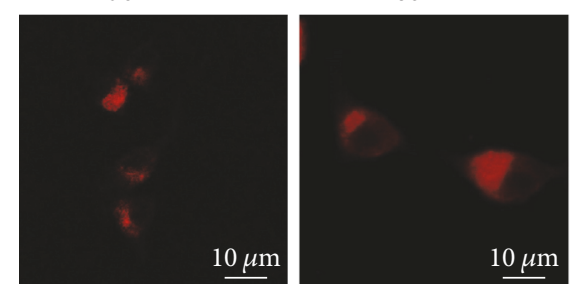

(b)

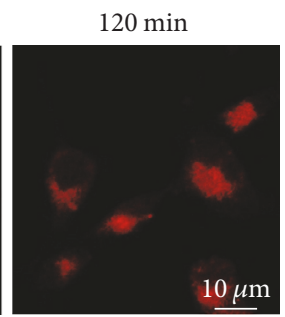

$\underline{10 \mu \mathrm{m}}$

(c)

FIGURE 9: Confocal microscopy imaging of the cellular uptake of the AIS (QD1) nanoconjugates by U-87 MG cells versus incubation time (30 min, $60 \mathrm{~min}$, and $120 \mathrm{~min}$ ): PL + bright field image (a), PL image (b), and plot of MFI $\times$ time (c).
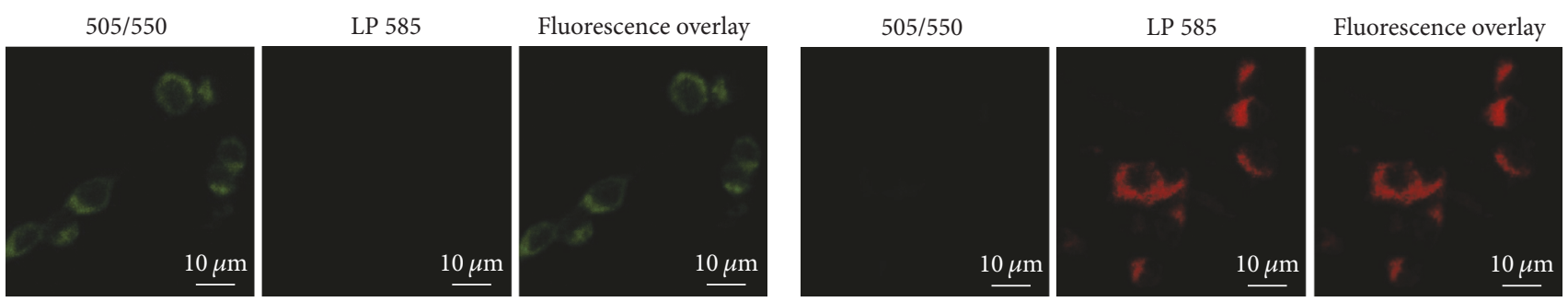

(a)

(b)

FIGURE 10: Fluorescence spectral imaging of U-87 MG cells separately treated for 30 min with green-emitting ZAIS (a) and red-emitting AIS (b) with PL emissions split by optical filters (green: 505/550 and red: LP 585) and overlaid PL image.

red-shift evidenced the growth of a $\mathrm{ZnS}$ layer resulting on the ZAIS core-shell nanostructures. TEM results indicated that monodispersed AIS and ZAIS QDs were produced with average sizes of $2.2 \mathrm{~nm}$ and $4.3 \mathrm{~nm}$, respectively. In addition, these nanoconjugates showed surface charge determined by zeta potential measurements typically ranging from $-43 \mathrm{mV}$ to $-46 \mathrm{mV}$ and hydrodynamic diameter from $38 \mathrm{~nm}$ up to $48 \mathrm{~nm}$ assessed by the DLS method. These results indicated that colloidal QD nanoconjugates were electrostatically stabilized by negatively charged CMC polymer ligand (i.e., carboxylic groups, $\mathrm{R}-\mathrm{COO}^{-}$). Moreover, the MTT results evidenced that they were preliminarily cytocompatible using in vitro assay with HEK $293 \mathrm{~T}$ and U-87 MG cells. Moreover, these novel AIS and ZAIS QDs surface modified by CMC showed appropriate intracellular photoluminescence upon incubation with HEK $293 \mathrm{~T}$ and U-87 MG cells, providing the effective function of cell bioimaging. Finally, these AIS and ZAIS QDs demonstrated red and green photoluminescent emissions, respectively, allowing effectively multiplexed bioimaging and biolabeling of costained glioma cells using confocal microscopy. Therefore, these bioconjugates offer promising nanoplatforms for potential in vitro and in vivo biomedical applications in multimodal bioimaging and targeting of cancer cells, opening a vast realm of possibilities to be explored in future researches. 


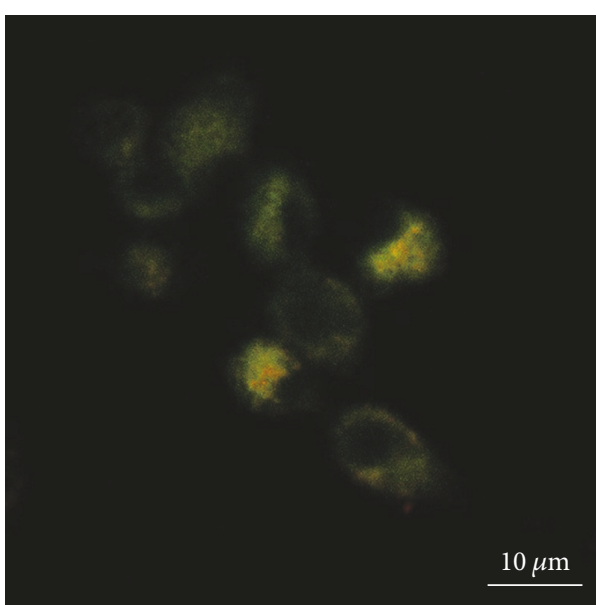

(a)

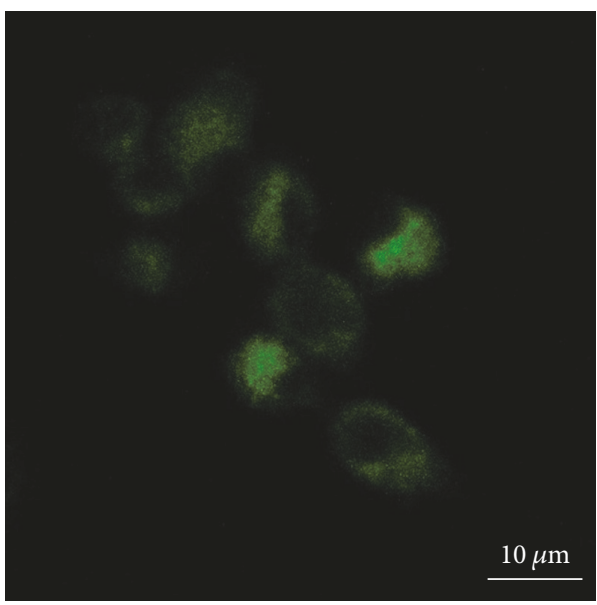

(c)

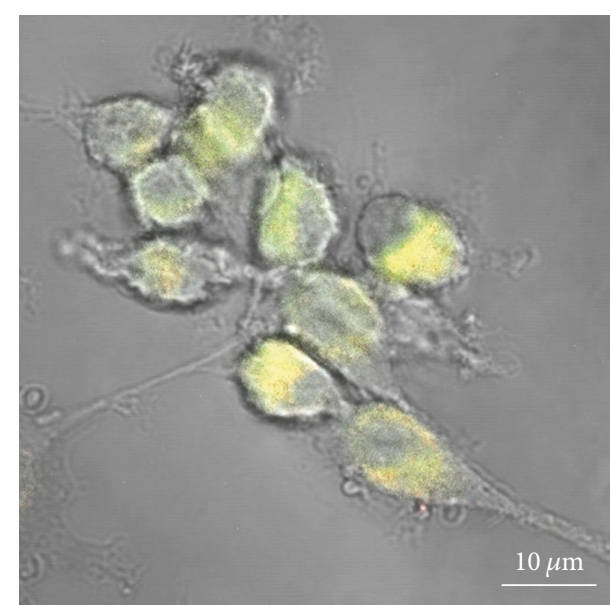

(b)

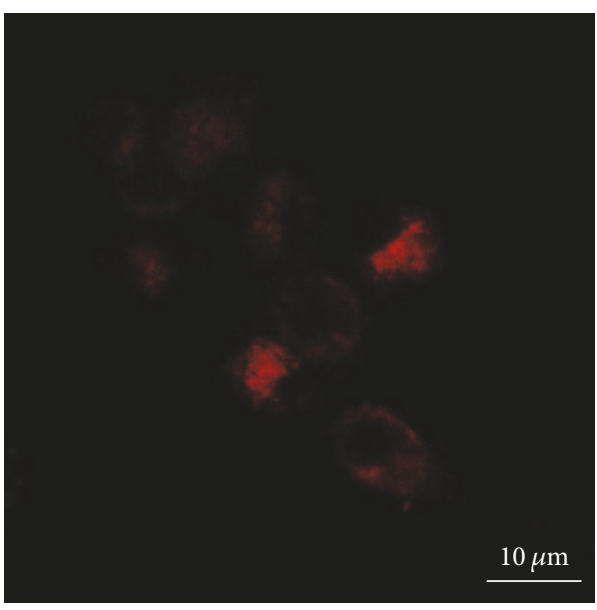

(d)

FIGURE 11: Multiplexed QD images of U-87 MG cells costained with AIS (QD1) + ZAIS (QD4): fluorescence overlay multicolor image (a); PL multicolor image overlaid with bright field image (b); PL image from filter 505/550 (green-emitting ZAIS) (c); and PL image from filter LP 585 (red-emitting AIS) (d).

\section{Conflicts of Interest}

The authors declare that there are no conflicts of interest regarding the publication of this article.

\section{Acknowledgments}

The authors acknowledge the financial support from the following Brazilian research agencies: CAPES (PROEX433/2010; PNPD; PROINFRA2010-2014), FAPEMIG (PPM00760-16; BCN-TEC 30030/12), CNPq (PQ1B-306306/20140; UNIVERSAL-457537/2014-0; PIBIC-2014/2015), and FINEP (CTINFRA-PROINFRA 2008/2010/2011). The authors express their gratitude to Professor Andréia Bicalho for the assistance with XRD analysis. Finally, the authors thank the staff at the Center of Nanoscience, Nanotechnology and Innovation (CeNano ${ }^{2}$ I)/CEMUCASI/UFMG for the spectroscopy analyses.

\section{References}

[1] K. Strebhardt and A. Ullrich, "Paul Ehrlich's magic bullet concept: 100 Years of progress," Nature Reviews Cancer, vol. 8, no. 6, pp. 473-480, 2008.

[2] A. M. Scott, J. D. Wolchok, and L. J. Old, "Antibody therapy of cancer," Nature Reviews Cancer, vol. 12, no. 4, pp. 278-287, 2012.

[3] H. Chen, W. Zhang, G. Zhu, J. Xie, and X. Chen, "Rethinking cancer nanotheranostics," Nature Reviews Materials, vol. 2, no. 7, p. 17024, 2017.

[4] R. Weissleder and M. J. Pittet, "Imaging in the era of molecular oncology," Nature, vol. 452, no. 7187, pp. 580-589, 2008.

[5] A. Jemal, F. Bray, M. M. Center, J. Ferlay, E. Ward, and D. Forman, "Global cancer statistics," CA: A Cancer Journal for Clinicians, vol. 61, no. 2, pp. 69-90, 2011.

[6] M. Fang, C.-W. Peng, D.-W. Pang, and Y. Li, "Quantum dots for cancer research: current status, remaining issues, and future perspectives," Cancer Biology \& Medicine, vol. 9, no. 3, pp. 151$163,2012$. 
[7] J. D. Lathia, S. C. Mack, E. E. Mulkearns-Hubert, C. L. L. Valentim, and J. N. Rich, "Cancer stem cells in glioblastoma," Genes \& Development, vol. 29, no. 12, pp. 1203-1217, 2015.

[8] H. Sontheimer, "Brain cancer: tumour cells on neighbourhood watch," Nature, vol. 528, no. 7580, pp. 49-50, 2015.

[9] Y. Cheng, R. A. Morshed, B. Auffinger, A. L. Tobias, and M. S. Lesniak, "Multifunctional nanoparticles for brain tumor imaging and therapy," Advanced Drug Delivery Reviews, vol. 66, pp. 42-57, 2014.

[10] W. Szopa, T. A. Burley, G. Kramer-Marek, and W. Kaspera, "Diagnostic and therapeutic biomarkers in glioblastoma: current status and future perspectives," BioMed Research International, vol. 2017, Article ID 8013575, 13 pages, 2017.

[11] N. Kuthala, R. Vankayala, Y. Li, C. Chiang, and K. C. Hwang, "Engineering novel targeted boron-10-enriched theranostic nanomedicine to combat against murine brain tumors via mr imaging-guided boron neutron capture therapy," Advanced Materials, vol. 29, no. 31, Article ID 1700850, 2017.

[12] M. C. Mabray, R. F. Barajas, and S. Cha, "Modern brain tumor imaging," Brain Tumor Research and Treatment, vol. 3, no. 1, pp. 8-23, 2015.

[13] S. Cha, "Update on brain tumor imaging: from anatomy to physiology," American Journal of Neuroradiology, vol. 27, no. 3, pp. 475-487, 2006.

[14] E.-K. Lim, T. Kim, S. Paik, S. Haam, Y.-M. Huh, and K. Lee, "Nanomaterials for theranostics: recent advances and future challenges," Chemical Reviews, vol. 115, no. 1, pp. 327-394, 2015.

[15] Y. Wang and L. Chen, "Quantum dots, lighting up the research and development of nanomedicine," Nanomedicine: Nanotechnology, Biology and Medicine, vol. 7, no. 4, pp. 385-402, 2011.

[16] H. Mansur, A. Mansur, S. Carvalho, Z. Lobato, M. I. Guedes, and M. d. Leite, "Surface biofunctionalized CdS and $\mathrm{ZnS}$ quantum dot nanoconjugates for nanomedicine and oncology: to be or not to be nanotoxic?" International Journal of Nanomedicine, vol. 11, pp. 4669-4690, 2016.

[17] F. P. Ramanery, A. A. P. Mansur, and H. S. Mansur, "Onestep colloidal synthesis of biocompatible water-soluble $\mathrm{ZnS}$ quantum dot/chitosan nanoconjugates," Nanoscale Research Letters, vol. 8, no. 1, pp. 1-13, 2013.

[18] E. Oh, R. Liu, A. Nel et al., "Meta-analysis of cellular toxicity for cadmium-containing quantum dots," Nature Nanotechnology, vol. 11, no. 5, pp. 479-486, 2016.

[19] G. Xu, S. Zeng, B. Zhang, M. T. Swihart, K.-T. Yong, and P. N. Prasad, "New generation cadmium-free quantum dots for biophotonics and nanomedicine," Chemical Reviews, vol. 116, no. 19, pp. 12234-12327, 2016.

[20] M. D. Regulacio, K. Y. Win, S. L. Lo et al., "Aqueous synthesis of highly luminescent $\mathrm{AgInS}_{2}-\mathrm{ZnS}$ quantum dots and their biological applications," Nanoscale, vol. 5, no. 6, pp. 2322-2327, 2013.

[21] H. C. Yoon, J. H. Oh, M. Ko, H. Yoo, and Y. R. Do, "Synthesis and characterization of green $\mathrm{Zn}-\mathrm{Ag}-\mathrm{In}-\mathrm{S}$ and red $\mathrm{Zn}-\mathrm{Cu}-\mathrm{In}-\mathrm{S}$ quantum dots for ultrahigh color quality of down-converted white LEDs," ACS Applied Materials \& Interfaces, vol. 7, no. 13, pp. 7342-7350, 2015.

[22] H. S. Mansur, A. A. P. Mansur, A. Soriano-Araújo, and Z. I. P. Lobato, "Beyond biocompatibility: an approach for the synthesis of $\mathrm{ZnS}$ quantum dot-chitosan nano-immunoconjugates for cancer diagnosis," Green Chemistry, vol. 17, no. 3, pp. 1820-1830, 2015.
[23] H. S. Mansur, A. A. P. Mansur, A. Soriano-Araújo, Z. I. P. Lobato, S. M. De Carvalho, and M. D. F. Leite, "Water-soluble nanoconjugates of quantum dot-chitosan-antibody for in vitro detection of cancer cells based on 'enzyme-free' fluoroimmunoassay," Materials Science and Engineering: C, vol. 52, pp. 61-71, 2015.

[24] A. A. P. Mansur, H. S. Mansur, A. Soriano-Araújo, and Z. I. P. Lobato, "Fluorescent nanohybrids based on quantum dotchitosan-antibody as potential cancer biomarkers," ACS Applied Materials \& Interfaces, vol. 6, no. 14, pp. 11403-11412, 2014.

[25] W. Cai, D.-W. Shin, K. Chen et al., "Peptide-labeled nearinfrared quantum dots for imaging tumor vasculature in living subjects," Nano Letters, vol. 6, no. 4, pp. 669-676, 2006.

[26] W. Cai, K. Chen, Z.-B. Li, S. S. Gambhir, and X. Chen, "Dualfunction probe for PET and near-infrared fluorescence imaging of tumor vasculature," The Journal of Nuclear Medicine, vol. 48, no. 11, pp. 1862-1870, 2007.

[27] A. Raevskaya, V. Lesnyak, D. Haubold et al., "A fine size selection of brightly luminescent water-soluble Ag-In-S and Ag-In-S/ZnS quantum dots," The Journal of Physical Chemistry C, vol. 121, no. 16, pp. 9032-9042, 2017.

[28] L. Borkovska, A. Romanyuk, V. Strelchuk et al., "Optical characterization of the $\operatorname{AgInS}_{2}$ nanocrystals synthesized in aqueous media under stoichiometric conditions," Materials Science in Semiconductor Processing, vol. 37, pp. 135-142, 2015.

[29] H. Zhong, Z. Bai, and B. Zou, "Tuning the luminescence properties of colloidal I-III-VI semiconductor nanocrystals for optoelectronics and biotechnology applications," The Journal of Physical Chemistry Letters, vol. 3, no. 21, pp. 3167-3175, 2012.

[30] J. Y. Chang, G. Q. Wang, C. Y. Cheng, W. X. Lin, and J. C. $\mathrm{Hsu}$, "Strategies for photoluminescence enhancement of $\mathrm{AgInS}_{2}$ quantum dots and their application as bioimaging probes," Journal of Materials Chemistry, vol. 22, pp. 10609-10618, 2012.

[31] D. F. Eaton, "Reference materials for fluorescence measurement," Pure and Applied Chemistry, vol. 60, no. 7, pp. 1107-1114, 1988.

[32] C. A. Schneider, W. S. Rasband, and K. W. Eliceiri, "NIH Image to ImageJ: 25 years of image analysis," Nature Methods, vol. 9, no. 7, pp. 671-675, 2012.

[33] T. Torimoto, T. Adachi, K.-I. Okazaki et al., "Facile synthesis of $\mathrm{ZnS}-\mathrm{AglnS}_{2}$ solid solution nanoparticles for a color-adjustable luminophore," Journal of the American Chemical Society, vol. 129, no. 41, pp. 12388-12389, 2007.

[34] J. Song, C. Ma, W. Zhang et al., "Bandgap and structure engineering via cation exchange: from binary $\mathrm{Ag}_{2} \mathrm{~S}$ to ternary $\mathrm{AgInS}_{2}$, quaternary AgZnInS alloy and AgZnInS/ZnS core/shell fluorescent nanocrystals for bioimaging," ACS Applied Materials \& Interfaces, vol. 8, no. 37, pp. 24826-24836, 2016.

[35] A. E. Raevskaya, Y. V. Panasiuk, O. L. Stroyuk et al., "Spectral and luminescent properties of $\mathrm{ZnO}-\mathrm{SiO}_{2}$ core-shell nanoparticles with size-selected $\mathrm{ZnO}$ cores," RSC Advances, vol. 4, no. 108, pp. 63393-63401, 2014.

[36] A. A. P. Mansur, F. P. Ramanery, L. C. Oliveira, and H. S. Mansur, "Carboxymethyl chitosan functionalization of $\mathrm{Bi}_{2} \mathrm{~S}_{3}$ quantum dots: towards eco-friendly fluorescent core-shell nanoprobes," Carbohydrate Polymers, vol. 146, pp. 455-466, 2016.

[37] K. Rajeshwar, N. R. De Tacconi, and C. R. Chenthamarakshan, "Semiconductor-based composite materials: preparation, properties, and performance," Chemistry of Materials, vol. 13, no. 9, pp. 2765-2782, 2001.

[38] P. Reiss, M. Protière, and L. Li, "Core/shell semiconductor nanocrystals," Small, vol. 5, no. 2, pp. 154-168, 2009. 
[39] M. L. A. Aguilera, M. Ortega-López, V. M. Sánchez Resendiz, J. A. Hernández, and M. A. González Trujillo, "Some physical properties of chalcopyrite and orthorhombic $\mathrm{AgInS}_{2}$ thin films prepared by spray pyrolysis," Materials Science and Engineering: $B$, vol. 102, no. 1-3, pp. 380-384, 2003.

[40] V. Uskoković, "Composites comprising cholesterol and carboxymethyl cellulose," Colloids and Surfaces B: Biointerfaces, vol. 61, no. 2, pp. 250-261, 2008.

[41] Y. J. Park, J. H. Oh, N. S. Han et al., "Photoluminescence of band gap states in $\mathrm{AgInS}_{2}$ nanoparticles," The Journal of Physical Chemistry C, vol. 118, no. 44, pp. 25677-25683, 2014.

[42] Y.-J. Yuan, D.-Q. Chen, M. Xiong et al., "Bandgap engineering of $(\operatorname{AgIn})_{x} \mathrm{Zn}_{2(1-x)} \mathrm{S}_{2}$ quantum dot photosensitizers for photocatalytic $\mathrm{H}_{2}$ generation," Applied Catalysis B: Environmental, vol. 204, pp. 58-66, 2017.

[43] D. Deng, J. Cao, L. Qu, S. Achilefu, and Y. Gu, "Highly luminescent water-soluble quaternary $\mathrm{Zn}-\mathrm{Ag}-\mathrm{In}-\mathrm{S}$ quantum dots for tumor cell-targeted imaging," Physical Chemistry Chemical Physics, vol. 15, no. 14, pp. 5078-5083, 2013.

[44] J. Song, C. Ma, W. Zhang et al., "Tumor cell-targeted $\mathrm{Zn}_{3} \mathrm{In}_{2} \mathrm{~S}_{6}$ and $\mathrm{Ag}-\mathrm{Zn}$-In-S quantum dots for color adjustable luminophores," Journal of Materials Chemistry B, vol. 4, no. 48, pp. 7909-7918, 2016.

[45] C. L. Salgado, A. A. P. Mansur, H. S. Mansur, and F. J. M. Monteiro, "Fluorescent bionanoprobes based on quantum dotchitosan-O-phospho-l-serine conjugates for labeling human bone marrow stromal cells," RSC Advances, vol. 4, no. 90, pp. 49016-49027, 2014.

[46] Y. Gong and D. Zhao, "In situ immobilization of mercury in water, soil, and sediment using carboxymethyl cellulose stabilized iron sulfide nanoparticles," in Novel Solutions to Water Pollution, vol. 1123 of ACS Symposium Series, pp. 61-77, American Chemical Society, Washington, DC, USA, 2013.

[47] A. A. P. Mansur, F. G. de Carvalho, R. L. Mansur, S. M. Carvalho, L. C. de Oliveira, and H. S. Mansur, "Carboxymethylcellulose/ZnCdS fluorescent quantum dot nanoconjugates for cancer cell bioimaging," International Journal of Biological Macromolecules, vol. 96, pp. 675-686, 2017.

[48] R. Dulbecco and G. Freeman, "Plaque production by the polyoma virus," Virology, vol. 8, no. 3, pp. 396-397, 1959.

[49] J. van der Valk, D. Brunner, K. De Smet et al., "Optimization of chemically defined cell culture media-replacing fetal bovine serum in mammalian in vitro methods," Toxicology in Vitro, vol. 24, no. 4, pp. 1053-1063, 2010.

[50] G. Gstraunthaler, "Alternatives to the use of fetal bovine serum: serum-free cell culture," ALTEX: Alternativen zu Tierexperimenten, vol. 20, no. 4, pp. 275-281, 2003.

[51] N. Oh and J.-H. Park, "Endocytosis and exocytosis of nanoparticles in mammalian cells," International Journal of Nanomedicine, vol. 9, no. 1, pp. 51-63, 2014.

[52] A. Albanese and W. C. W. Chan, "Effect of gold nanoparticle aggregation on cell uptake and toxicity," ACS Nano, vol. 5, no. 7, pp. 5478-5489, 2011.

[53] S. Sharifi, S. Behzadi, S. Laurent, M. Laird Forrest, P. Stroeve, and M. Mahmoudi, "Toxicity of nanomaterials," Chemical Society Reviews, vol. 41, no. 6, pp. 2323-2343, 2012.

[54] W. Jiang, B. Y. S. Kim, J. T. Rutka, and W. C. W. Chan, "Nanoparticle-mediated cellular response is size-dependent," Nature Nanotechnology, vol. 3, no. 3, pp. 145-150, 2008.

[55] K. M. Tsoi, Q. Dai, B. A. Alman, and W. C. W. Chan, "Are quantum dots toxic? Exploring the discrepancy between cell culture and animal studies," Accounts of Chemical Research, vol. 46, no. 3, pp. 662-671, 2013.

[56] M. Allen, M. Bjerke, H. Edlund, S. Nelander, and B. Westermark, "Origin of the U87MG glioma cell line: good news and bad news," Science Translational Medicine, vol. 8, no. 354, Article ID 354re3, 2016.

[57] J. L. Sowers, K. M. Johnson, C. Conrad, J. T. Patterson, and L. C. Sowers, "The role of inflammation in brain cancer," in Inflammation and Cancer-Advances in Experimental Medicine and Biology, vol. 816, Springer, Basel, Swiss, 2014.

[58] S. Vaidyanathan, B. G. Orr, and M. M. Banaszak Holl, "Detergent induction of HEK 293A cell membrane permeability measured under quiescent and superfusion conditions using whole cell patch clamp," The Journal of Physical Chemistry B, vol. 118, no. 8, pp. 2112-2123, 2014.

[59] L. Damalakiene, V. Karabanovas, S. Bagdonas, M. Valius, and R. Rotomskis, "Intracellular distribution of nontargeted quantum dots after natural uptake and microinjection," International Journal of Nanomedicine, vol. 8, pp. 555-568, 2013.

[60] B. Zhang, C. Yang, Y. Gao et al., "Engineering quantum dots with different emission wavelengths and specific fluorescence lifetimes for spectrally and temporally multiplexed imaging of cells," Nanotheranostics, vol. 1, no. 1, pp. 131-140, 2017.

[61] Y. Xing, Q. Chaudry, C. Shen et al., "Bioconjugated quantum dots for multiplexed and quantitative immunohistochemistry," Nature Protocols, vol. 2, no. 5, pp. 1152-1165, 2007.

[62] F. T. Lee-Montiel, P. Li, and P. I. Imoukhuede, "Quantum dot multiplexing for the profiling of cellular receptors," Nanoscale, vol. 7, no. 44, pp. 18504-18514, 2015.

[63] H. Xu, J. Xu, X. Wang, D. Wu, Z. G. Chen, and A. Y. Wang, "Quantum dot-based, quantitative, and multiplexed assay for tissue staining," ACS Applied Materials Interfaces, vol. 5, no. 8, pp. 2901-2907, 2013.

[64] Q. T. Nguyen and R. Y. Tsien, "Fluorescence-guided surgery with live molecular navigation-a new cutting edge," Nature Reviews Cancer, vol. 13, no. 9, pp. 653-662, 2013.

[65] A. Madhankumar, O. D. Mrowczynski, S. R. Patel et al., "Interleukin-13 conjugated quantum dots for identification of glioma initiating cells and their extracellular vesicles," Acta Biomaterialia, vol. 58, pp. 205-213, 2017. 


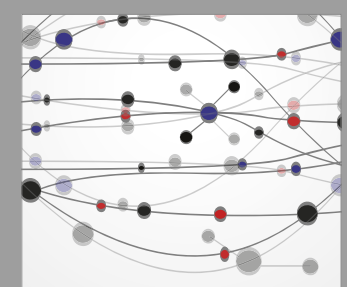

The Scientific World Journal
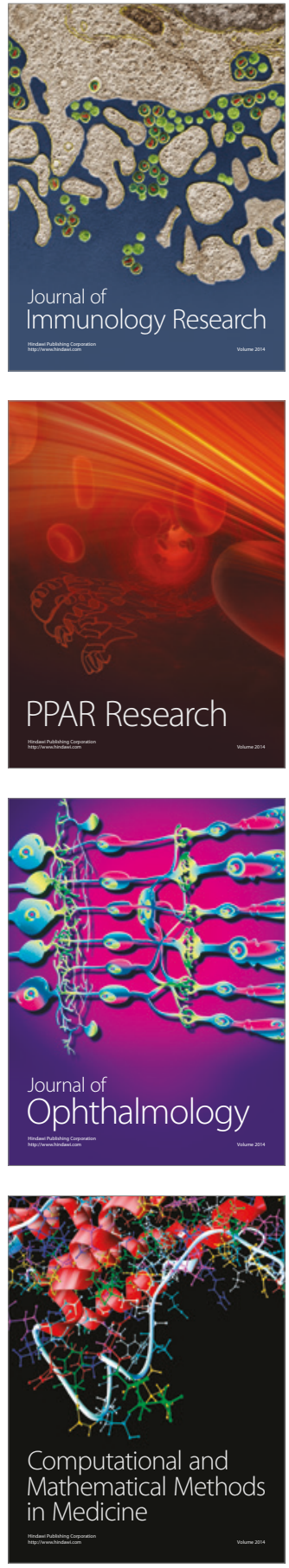

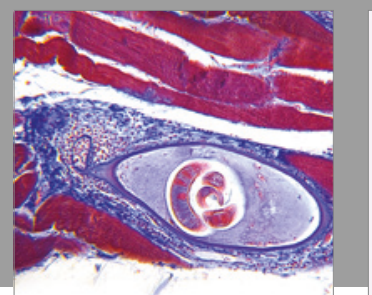

Gastroenterology Research and Practice
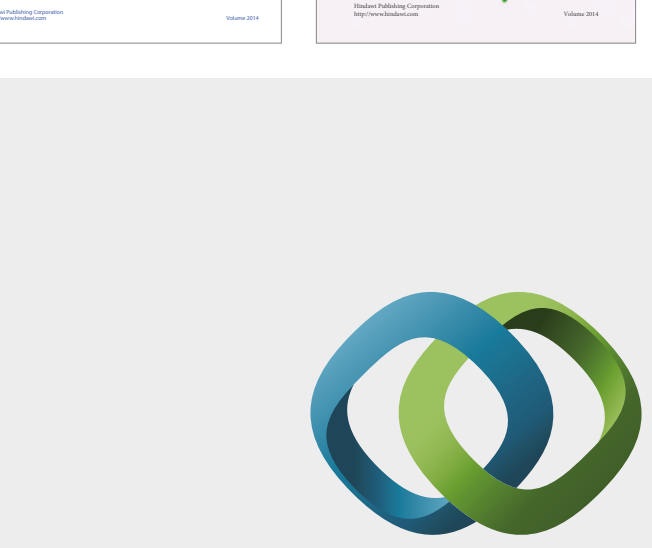

\section{Hindawi}

Submit your manuscripts at

https://www.hindawi.com
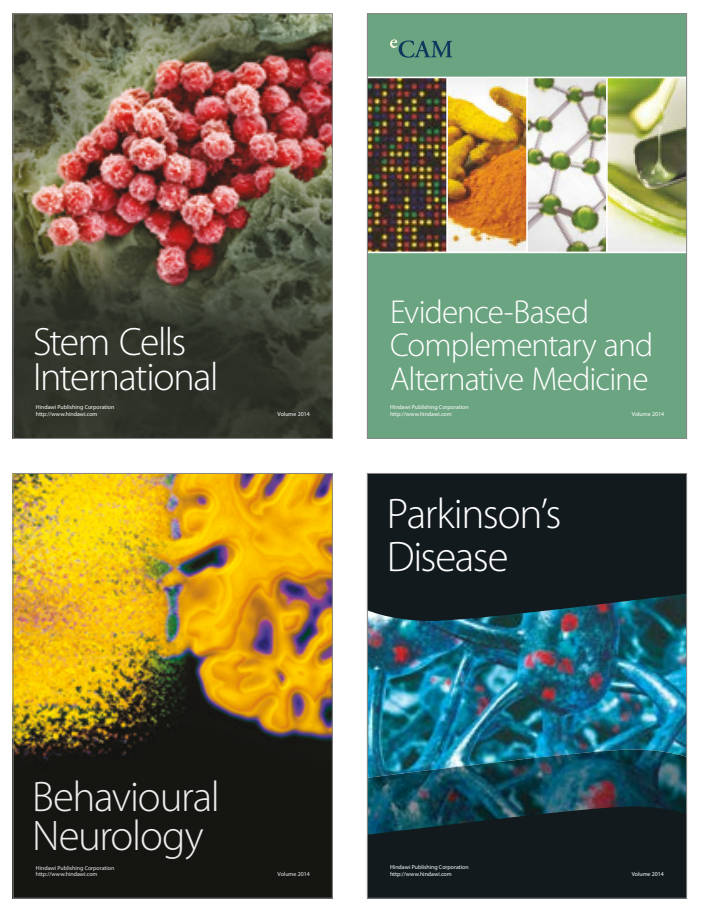
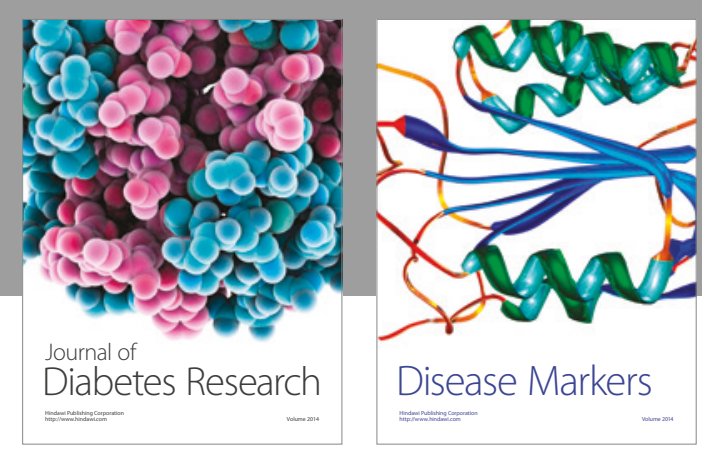

Disease Markers
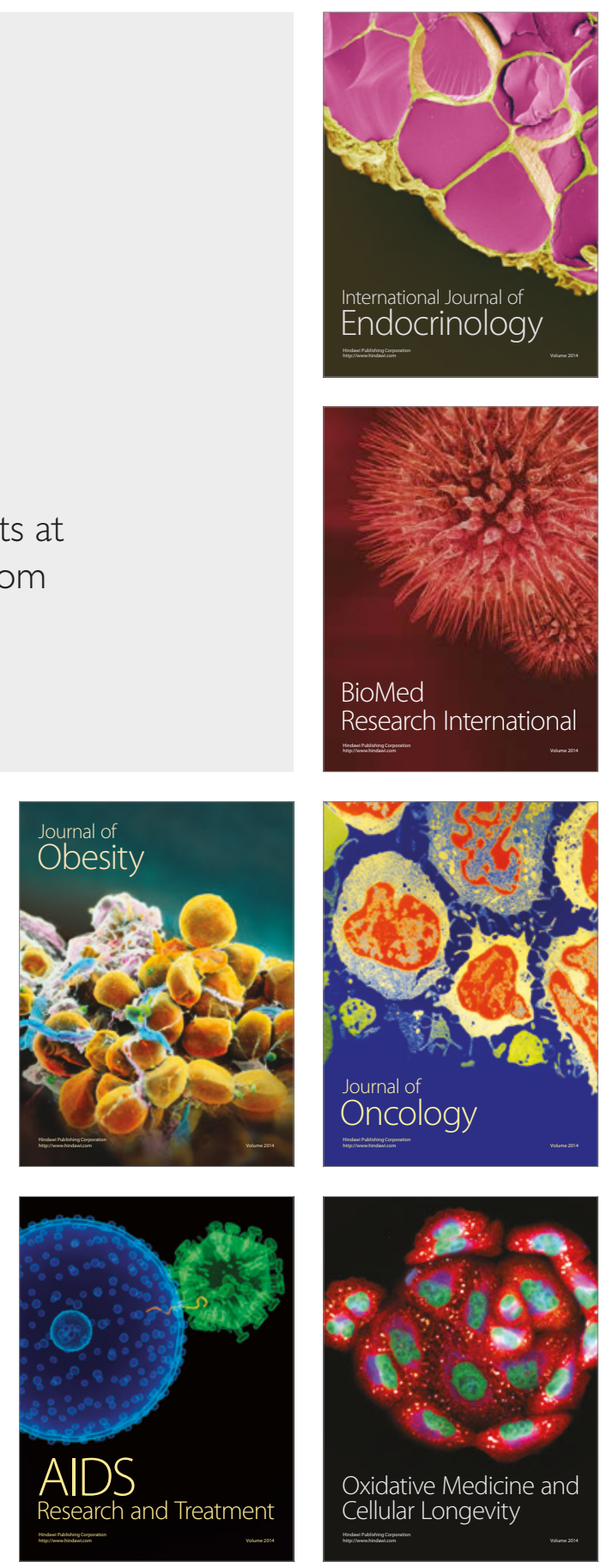